\title{
A COMPARATIVE STUDY OF HOW BRITISH TITS ENCODE PREDATOR THREAT IN THEIR
} MOBBING CALLS

Nora V Carlson ${ }^{1}$, Susan D Healy ${ }^{1}$, Christopher N Templeton ${ }^{1,2}$

${ }^{1}$ School of Biology, University of St Andrews, Scotland, UK

2 Department of Biology, Pacific University, Forest Grove, OR, USA

Word count: 9120

*Correspondence: Nora V Carlson

School of Biology

University of St Andrews

Harold Mitchell Building

St Andrews, Fife

KY16 9TH, Scotland, UK

$+44(0) 7541-967008$

nc54@st-andrews.ac.uk

Co-correspondence: Christopher N Templeton,

Department of Biology,

Pacific University,

2043 College Way 
Forest Grove, Oregon, 97116, USA

+1 503-352-3149

templeton@pacificu.edu 
1 A COMPARATIVE STUDY OF HOW BRITISH TITS ENCODE PREDATOR THREAT IN THEIR

2 MOBBING CALLS

4 Many species use anti-predator vocalizations to signal information about potential

5 predators, including the level of threat posed by a particular predator. It is not clear,

6 however, why only some prey species do this. Because they use multiple mechanisms to

7 encode threat specific information about predators, North American Paridae species have

8 been a particularly useful model for studying anti-predatory signals. Paridae as a group

9 are also useful for examining phylogenetic conservation of vocal signals because all of

10 these species (at least those studied previously) employ similar ways of encoding

11 information about predatory threat. To test whether the ways in which predator threat

12 information is encoded (here measured by a bird's vocal output) are conserved across a

13 family with similar vocalizations, we used taxidermy mounts to simulate low and high

14 threat predators to induce mobbing in six species across five genera of British Paridae.

15 We found that, like North American species, British tits all increased their call rate in

16 response to predators compared with non-threatening control mounts, but they all varied

17 in the number and types of additional ways they encoded this information. Some species

18 (blue \& willow tits) used all four ways to differentiate between different threat predators,

19 while others used only two (crested tits), one (great \& coal tits) or none at all (willow

20 tits). The variation in the way each species encoded predator threat information in their

21 calls was not explained by phylogenetic relatedness or by variation in life history. To

22 better understand patterns of information encoding across related species, we suggest that

23 playback experiments to determine how encoded information is used by conspecifics and 
24 heterospecifics might provide insights about why some species encode information about 25 predator threat in multiple ways.

26

27 KEY WORDS: acoustic communication, anti-predator behaviour, information encoding, 28 mobbing, Paridae, predator-prey dynamics 
A COMPARATIVE STUDY OF HOW BRITISH TITS ENCODE PREDATOR THREAT IN THEIR

2

3

4 Many species, across a wide range of taxa, use vocalizations to warn about and

5 defend against predators (Gill \& Bierema, 2013; Klump \& Shalter, 1984;

6 Slobodchikoff, 2010; Townsend \& Manser, 2013). These anti-predator vocalizations

7 can provide information about a predator's size, speed, distance, type/category, and

8 even behaviour (Evans, Macedonia, \& Marler, 1993; Gill \& Bierema, 2013; Griesser,

9 2008; Marler, 1955; Murphy, Lea, \& Zuberbühler, 2013; Placer \& Slobodchikoff, $2000 ; 2004)$.

11

12 Species vary substantially in the ways they encode information to communicate about 13 predators. Meerkats, Suricata suricatta, for example, increase call rate along with a 14 number of fine-scale acoustic parameters to communicate an increase in the danger a 15 predator poses (Manser, 2001), while yellow warblers Setophaga petechia use the likelihood of producing a particular call type (seet) to signal the presence of a nest predator (Gill \& Sealy, 2004). Other species use strategies that range from employing a single way of encoding information to combining multiple ways of encoding information. Furthermore, some strategies may be driven entirely by the signaller's internal state while others reference external stimuli (Gill \& Bierema, 2013; Magrath, Haff, Fallow, \& Radford, 2014). American crows Corvus brachyrhynchos, for example, use longer calls and higher call rate to signal increased danger (Yorzinski \& Vehrencamp, 2009), while vervet monkeys Chlorocebus pygerythrus indicate not only predator type (leopard, eagle, and snake) but degree of danger through the propensity to use different call types (predator types) and an increase in the number of 
26 elements (degree of danger; Seyfarth, Cheney, \& Marler, 1980). It is not clear why

27 this variability across different taxa and species in encoding mechanisms exists. But,

28 as many closely related species share similar vocalizations and may therefore share

29 similar ways of encoding predator threat information, it might be that phylogenetic

30 relationships provide part of the explanation (Hailman, 1989; Latimer, 1977; Randler, 31 2012)

32

33 The North American Paridae have been widely used to study the ways in which

34 individuals encode predator threat particularly in their mobbing calls. Mobbing calls

35 generally serve to harass the predator and/or to recruit conspecifics and

36 heterospecifics for that harassment (Curio, 1978). In their mobbing calls, North

37 American Paridae encode not only the presence or absence of a predator but they also

38 differentiate between predators of different threat levels. These species indicate the

39 presence of a higher threat predator by increases in: 1) call rate (black-capped

40 chickadees Poecile atricapillus, Carolina chickadees Poecile carolinensis, mountain

41 chickadees Poecile gambeli, and tufted titmice Baeolophus bicolor; Baker \& Becker,

42 2002; Bartmess-LeVasseur, Branch, Browning, Owens, \& Freeberg, 2010; Billings,

43 Greene, \& La Lucia Jensen, 2015; Hetrick \& Sieving, 2011; Templeton, Greene, \&

44 Davis, 2005); 2) the number of elements in their calls (black-capped chickadees,

45 Carolina chickadees, mountain chickadees, and tufted titmice; (Baker \& Becker,

46 2002; Bartmess-LeVasseur et al., 2010; Billings et al., 2015; Courter \& Ritchison,

47 2010; Hetrick \& Sieving, 2011; Sieving, Hetrick, \& Avery, 2010; Soard \& Ritchison,

48 2009; Templeton et al., 2005); 3) the propensity to produce particular call types

49 (tufted titmice and black-capped chickadees; Clemmons \& Lambrechts, 1992; Sieving

50 et al., 2010); and 4) the proportion of one call type used across mobbing events 
51 (black-capped chickadees; Baker \& Becker, 2002). Of the North American species,

52 black-capped chickadees have been shown to use all four of these ways of encoding

53 information in response to predators of different levels of threat. While the remaining

54 species have not been tested for all of the four ways, the available evidence suggests

55 that they likely behave in the same fashion as black-capped chickadees and there is no

56 indication that any of these species do not use any of the four ways of encoding

57 information. The lack of evidence to the contrary combined with data from the out-

58 group, Japanese great tits, Parus minor, which share the four ways with black-capped

59 chickadees, has led to the assumption that all Paridae species encode predator threat

60 information in their mobbing calls using this particular suite of changes to their

61 vocalizations (Hetrick \& Sieving, 2011; Langham, Contreas \& Sieving, 2006; Suzuki,

62 2014; Wilson \& Mennill, 2011).

63

64 As only a small number of the Paridae have actually been tested and most of the

65 species tested are from the same genus (Poecile; Johansson et al., 2013), providing a

66 general explanation for the ways in which animals encode predator threat is not

67 straightforward. To test experimentally the degree to which phylogenetic

68 conservatism might explain the distribution of encoding mechanisms within families,

69 we induced mobbing events in flocks of tits found in the UK (six species across five

70 genera) by simulating predator encounters using robotic taxidermy mounts of

71 predators representing different threat levels. We then examined whether each of

72 these species 1) differentiated between predators and non-predators in their mobbing

73 calls, 2) differentiated between high and low threat predators, and 3) used the same

74 four ways of encoding predator threat as the previously-tested Parid species. Here we

75 use the term 'encode' simply to denote that the calls produced in response to different 
76 predators are statistically different and that they therefore have the potential to

77 provide reliable information to receivers. Without playback experiments we cannot

78 confirm that receivers decode and use this information.

79

80 We used these data to test whether phylogeny explains the number and ways of

81 encoding information used by a given species, making the following predictions: 1) If

82 the ways of encoding information are conserved within the Pariadae, UK tit species

83 should use all four ways of encoding information to differentiate predators from non-

84 threats, and differentiate between predators of different threat levels. 2) If, however,

85 any of these species vary in the way they encode information about predators, the

86 pattern of relatedness should at least roughly match these differences such that those

87 species that are more closely related (e.g. marsh and willow tits in the genus Poecile)

88 to be more similar in the ways in which they encode information than those that are

89 more distantly related (e.g. marsh tits in the genus Poecile and blue tits in the genus

90 Cyanistes).

91

92 METHODS

93

94 Study sites

95

96 We conducted experiments from January to March 2014 and 2015 in four general

97 geographical regions in the UK (Figure 1a), each of which had feeders at a number of

98 different sites. Blue tits, Cyanistes caeruleus, great tits, Parus major, and coal tits,

99 Periparus ater, are found across the UK; crested tits, Lophophanes cristatus, occur

100 only in northern Scotland; marsh, Poecile palustris, and willow, Poecile montanus, 
101 tits occur only in the southern regions of the UK. To test blue, great, and coal tits we

102 used feeders in and around St Andrews, Fife (latitude, longitude; 56.331247, -

$1032.838451 ; n=23$ feeder locations) from January-March 2014. To test crested tits

104 along with blue, great and coal tits we used feeders in the north-western Cairngorm

105 mountains in Scotland (57.191208, -3.779156; $\mathrm{n}=15$ feeder locations) from January-

106 March 2015. To test willow tits along with blue, great, and coal tits, we used feeders

107 in Doncaster $(53.519235,-1.131355)$ and Newcastle upon Tyne (55.053305, -

108 1.644546) from January-March $2015(\mathrm{n}=7$ feeder locations). To test marsh tits along

109 with blue, great, and coal tits we used feeders in Monk's Wood near Cambridge

110 (52.401114, $-0.238468 ; \mathrm{n}=9$ feeder locations) from January-March 2015. Feeders

111 were filled with black-oil sunflower seeds and peanuts and placed in either

112 parks/forests or private gardens. To ensure that birds had enough time to locate and

113 become accustomed to using the feeders, all of the bird feeders were put up a

114 minimum of two weeks before we began the experiment.

115 

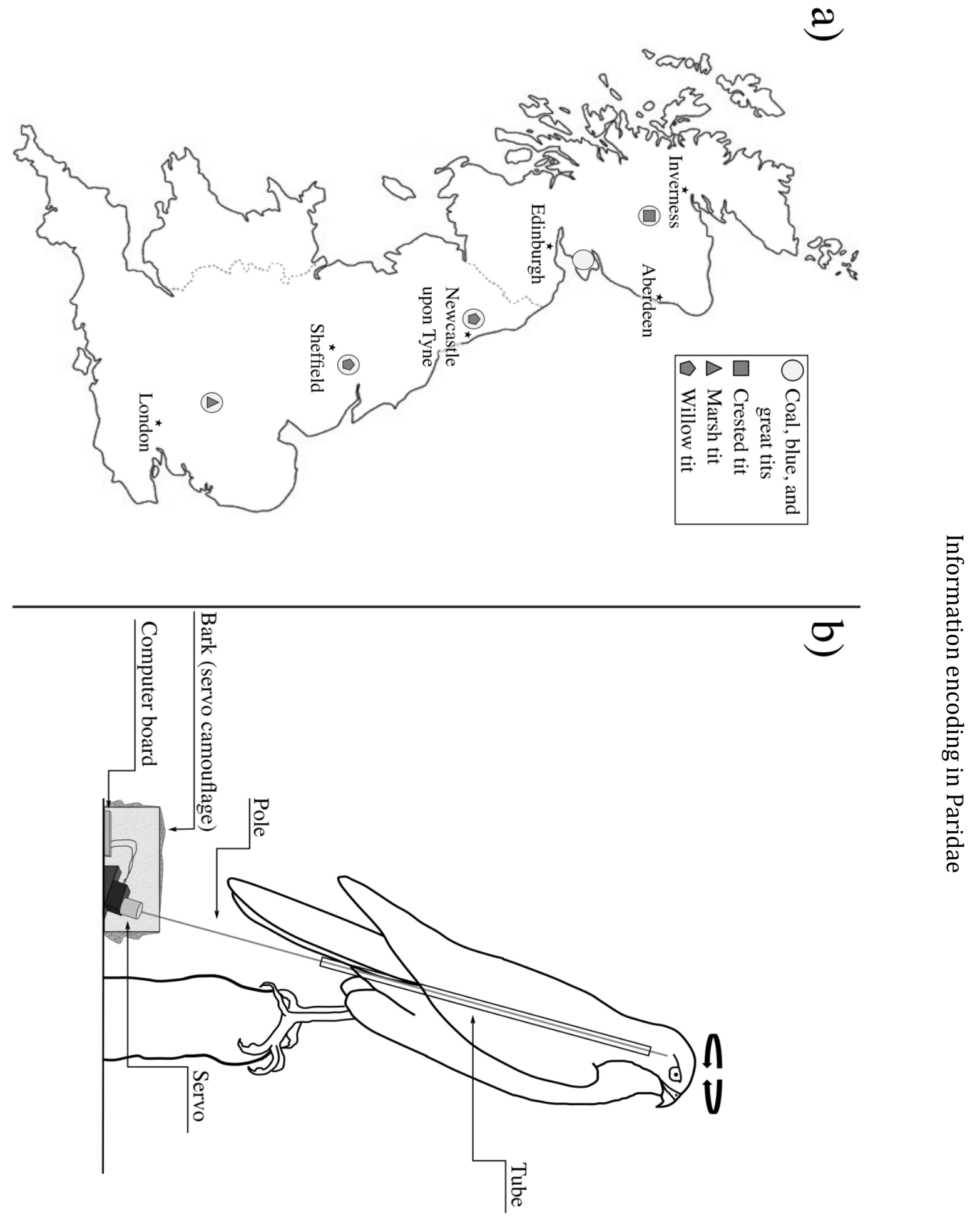


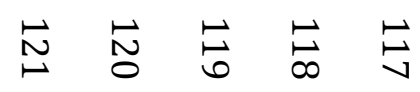

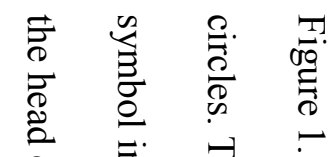

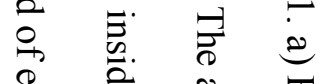

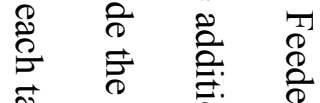

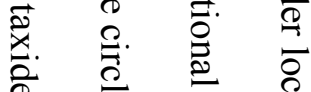

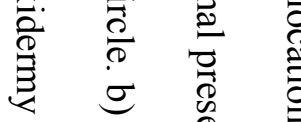

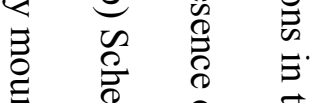

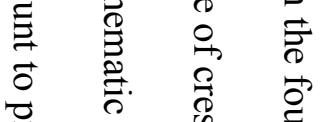

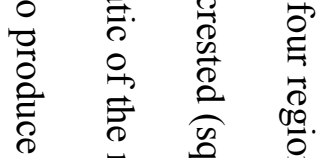

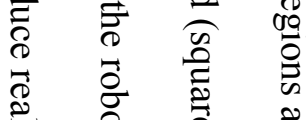

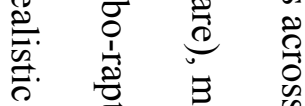

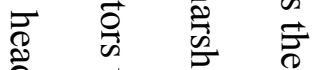

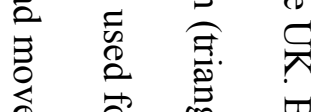

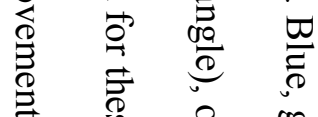

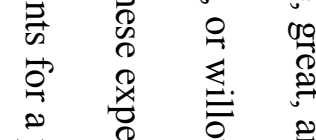

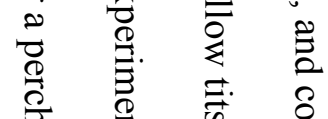



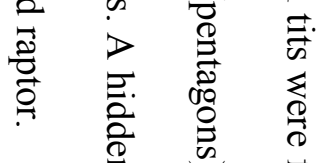

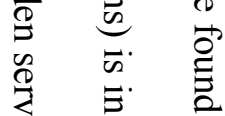

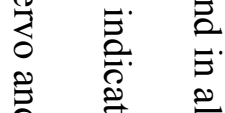

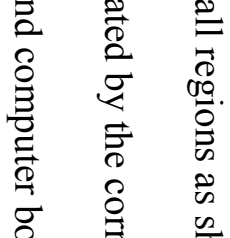

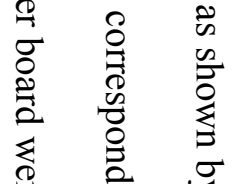

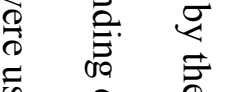

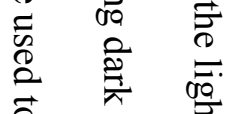

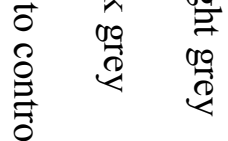




\section{Stimuli}

123

124 To test whether and how the tit species encode information about predator threat in

125 their mobbing calls we simulated encounters with three common British species,

126 which vary dramatically in the level of threat they pose to adult tits: 1) sparrowhawks,

127 Accipiter nisus, are high-threat predators for tits and prey almost exclusively on small

128 to medium sized birds including tit species (Curio, Klump, \& Regelmann, 1983;

129 Millon, Nielsen, Bretagnolle, \& Møller, 2009; Petty, Patterson, Anderson, Little, \&

130 Davison, 1995); 2) common buzzards, Buteo buteo, are low-threat predators for tits

131 as, although the majority of their $\operatorname{diet}(\sim 73 \%)$ made up of mammals and larger birds

132 such as pigeons, buzzards do occasionally eat small passerines $(\sim 16 \%$ of their diet;

133 Graham, Redpath, \& Thirgood, 1995), including tit species (Swann \& Etheridge,

134 2009); 3) grey partridges, Pedrix pedrix, were used as a control to ensure that the tit

135 species responded to the specific features of the predators and not simply to the

136 presence of a moving taxidermy bird. This species is found across the UK, is similar

137 in size to a sparrowhawk, but as it does not eat birds it poses no threat to tit species

138 (Šálek, Marhoul, Pintír, Kopecký, \& Slabý, 2004).

139

140 We used custom-made robotic taxidermy mounts of each species (Carlson et al.

141 submitted; Figure 1b) to elicit mobbing responses by the tits. We used two different

142 mounts of each species to reduce pseudoreplication. Our mounts included: one male

143 juvenile and one female adult sparrowhawk, two adult female buzzards, and two adult

144 male grey partridges. All mounts were perched on a tree branch or log, and their

145 heads rotated to mimic natural perched head movements. An Arduino computer board

146 (Arduino Duemilanove from Arduino LLC, https://www.arduino.cc) controlled a 
147 servo motor, which was programmed with 15 different commands that controlled the

148 head movement of the mounts to create a series of movements that mimicked natural

149 behaviour. These 15 commands were the same for all three types of stimulus and the

150 head moved for the entire time the mount was exposed. The total movement of the

151 head ranged $\sim 100^{\circ}$ and as the chest of the mounts faced the feeder, the head faced in

152 the direction of the bird feeder and the nearby surrounding cover all of the time

153 (Figure 1b; Book \& Freeberg, 2015).

154

155 Predator presentations

156

157 At each study site we presented birds with all three treatments (sparrowhawk,

158 buzzard, partridge) in a randomized order; the mount exemplar for each presentation

159 was selected randomly. We conducted experiments from one hour after dawn to one

160 hour before dusk to allow the birds time to recover from the presentations and allow

161 sufficient time to forage in preparation for overnight, as these presentations were all

162 carried out during the winter (Jan-March). We separated all buzzard and sparrowhawk

163 presentations and most control and predator presentations by a minimum of 8 hours at

164 each feeder location. Due to time constraints at some study sites, on occasion if we

165 presented the control (partridge) first and the birds continued to feed normally, we

166 waited for 15 minutes and then presented a predator trial (sparrowhawk $\mathrm{n}=6$,

167 buzzard $n=5$ trials). We excluded from the analyses those trials in which birds

168 obviously responded to something other than the stimulus (e.g. when we observed a

169 sparrowhawk flying overhead or initial behaviour suggesting birds had encountered a

170 predator just before we arrived; $n=7$ ). At some locations the focal species were not 
171 present for one or more trials and thus we collected data for fewer than three

172 treatments $(\mathrm{n}=9$ sites $)$.

173

174 We began presentations once we had confirmed the presence of the focal species

175 (acoustically or visually) near the feeder. We placed the taxidermy mount on a $1.5 \mathrm{~m}$

176 pole approximately $2 \mathrm{~m}$ from the bird feeder. Because head orientation is important in

177 predator threat assessment (Book \& Freeberg, 2015), we ensured that the mount faced

178 the bird feeder in all trials. We then retreated to a minimum distance of $4 \mathrm{~m}$ away and

179 hid behind cover. A trial began when an individual of the focal species either: 1) came

180 within $5 \mathrm{~m}$ of the mount; 2) came within $7 \mathrm{~m}$ of the mount with its body and head

181 oriented towards the mount for 20 seconds more than once in 2 minutes; or 3) began

182 mobbing the mount, by producing mobbing calls, rapidly changing perches, and wing

183 flicking while oriented towards the mount, or flying at the mount in an aggressive

184 fashion. Starting at this time point, we recorded when birds began to mob, and all

185 vocalizations that were produced for 5 minutes before removing the mount. Distances

186 were not physically marked in the field but, prior to beginning the manipulations, the

187 researchers were trained to determine by eye when birds were within 3,5 , and 7

188 meters of the mount. We recorded all trials with a Sennheiser ME 66 super-cardioid

189 microphone (Sennheiser Electronics, Hanover, Germany) and a Marantz PMD660

190 solid-state sound recorder (Marantz America, LLC., Mahwah, N.J., USA) with a bit-

191 depth of 24 bits and a sampling rate of $48 \mathrm{kHz}$.

192

193 At each simulated predator encounter we recorded the total number of individuals of

194 each species present and kept track of which species met any of the above mobbing

195 criteria, and therefore was considered to participate in the mobbing event. Due to 
196 environmental conditions and the variation in flock size (mean \pm standard error: $7.47 \pm$

1970.40 individuals/flock) and composition (number of species: $2.86 \pm 0.09$

198 species/flock), sample sizes varied across species: blue: $\mathrm{n}=47$ locations (control $\mathrm{n}=$

19941 , buzzard $n=42$, sparrowhawk $n=43$ ), great: $n=43$ locations (control $n=35$,

200 buzzard $n=41$, sparrowhawk $n=42$ ), coal: $n=41$ locations (control $n=34$, buzzard

$201 \mathrm{n}=35$, sparrowhawk $\mathrm{n}=36$ ), crested: $\mathrm{n}=14$ locations $($ control $\mathrm{n}=14$, buzzard $\mathrm{n}=$

20214 , sparrowhawk $n=13$ ), marsh: $n=9$ locations (control $n=9$, buzzard $n=9$,

203 sparrowhawk $\mathrm{n}=9$ ), and willow: $\mathrm{n}=7$ locations ( control $\mathrm{n}=7$, buzzard $\mathrm{n}=6$,

204 sparrowhawk $\mathrm{n}=7$ ), as did the average number of conspecifics present during a trial

205 (mean \pm standard error): blue: $3.00 \pm 0.21$, great: $2.37 \pm 0.14$, coal: $3.51 \pm 0.38$,

206 crested: $1.73 \pm 0.11$, marsh: $1.59 \pm 0.10$, and willow: $1.52 \pm 0.11$.

Ethical note

210 All of this work was approved by the University of St Andrews School of Biology

211 Ethics Committee (01112013) and Scottish National Heritage, and followed

212 ASAB/ABS guidelines for treatment of animals in research. As we conducted

213 predator presentations during the winter months, we restricted our simulated predator

214 encounters to the period from one hour after sunrise to one hour before sundown so

215 that birds could prepare for, and recover from, the hours of darkness. As predator

216 encounters are stressful for the animals involved, we limited predator presentations to

2175 minutes once individuals began to respond. We then removed the stimulus and left

218 the area as quickly as possible to allow the individuals to recover and return to

219 feeding. 
222 Acoustic analysis

223

224 For all acoustic analyses, we used Raven Pro v 1.5 software (Bioacoustics Research

225 Program, 2014) with a fast Fourier transform (FFT) size of 1050 samples, a Hann

226 window function, and a spectrogram frequency grid resolution of $23.04 \mathrm{~Hz}$. We

227 analyzed all calls produced within three minutes of the onset of mobbing by manually

228 selecting all calls and visually categorizing them by call type and call features (Table

229 1, Figure 2). All call types were clearly distinguished from one another as they were

230 classed into different types based on clearly visible structural differences.

231 Additionally, each species has a unique repertoire of calls making species

232 identification relatively straightforward even when multiple species were calling

233 during a trial (Table 1, Figure 2). To confirm the reliability of the categorization of

234 calls by NC, we asked six people to categorize the calls. Nearly all of the

235 classifications (89\%) had high repeatability across individuals (inter-class correlation

236 (ICC) values > 0.80; Nakagawa \& Schielzeth, 2010). The four calls that received

237 scores below 0.80 all included subtle variation, and so were re-scored by an individual

238 familiar with Paridae vocalizations. Repeated scores conducted by this trained

239 individual ranged from $0.77-1.0$, with only one call type (short calls) receiving an

240 ICC score below 0.80. In instances in which multiple calls overlapped it could have

241 been more difficult to determine the number or type of elements, but this occurred

242 infrequently and closer examination of each instance allowed the number of elements

243 to be determined. 
a)

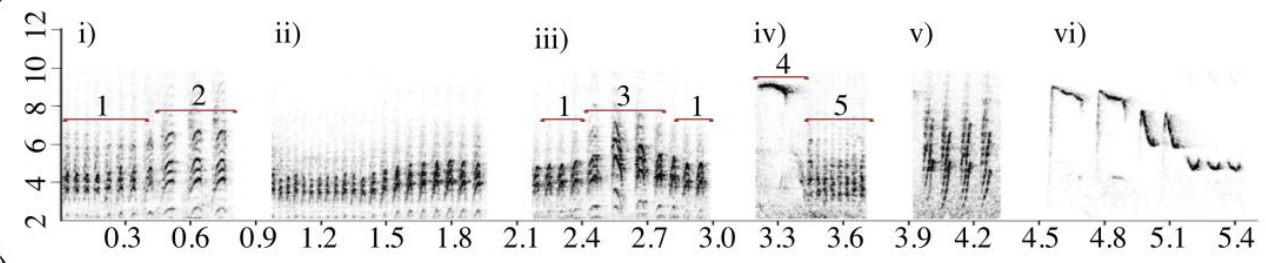

b)

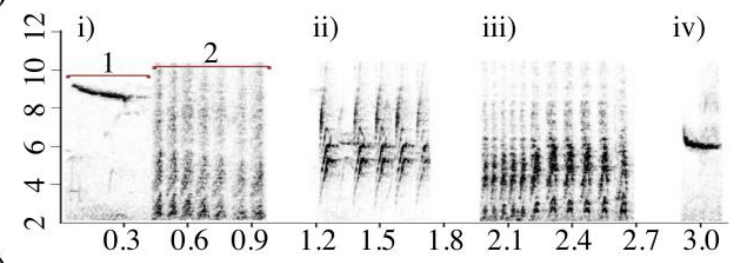

c)

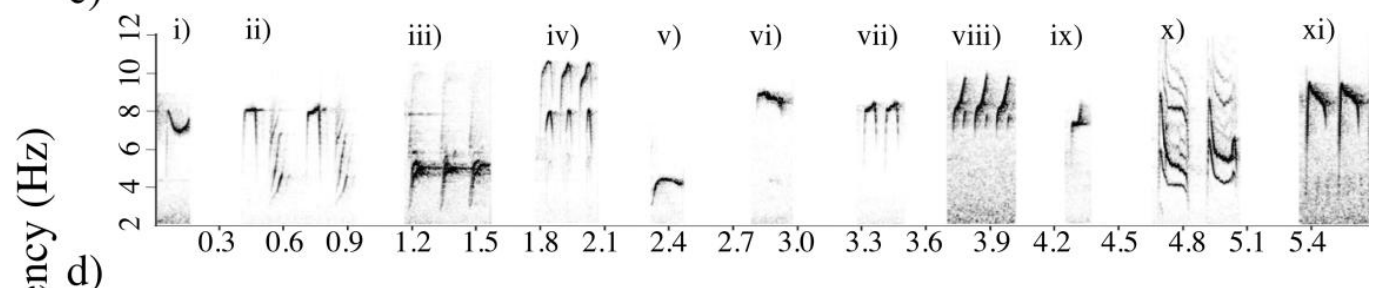

d)

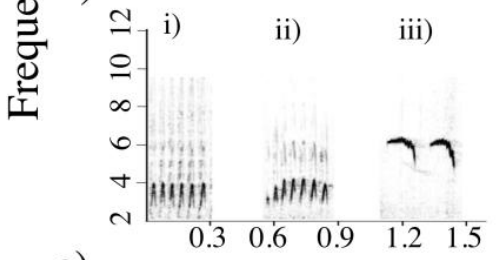

e)

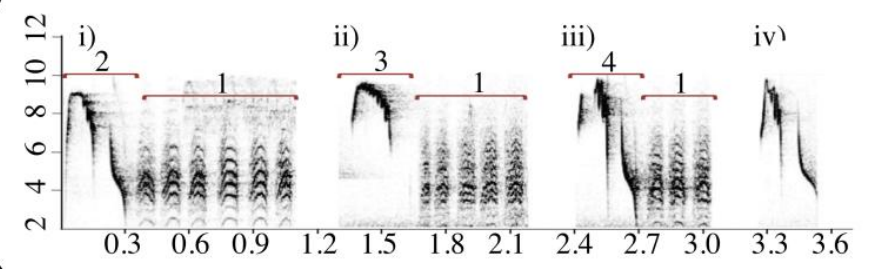

f)

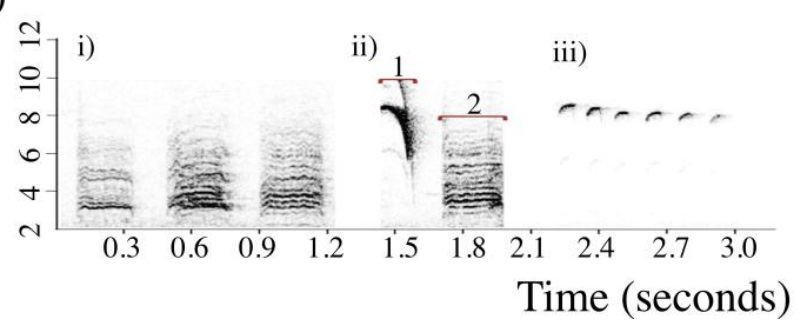

247 Figure 2. Spectrograms of UK tit mobbing calls. a) Blue tits: i-iv) churr call with 1)

248 normal D elements and 2) exit elements, ii) frequency-modulated call, 3) mid

249 elements, 4) introductory (intro) element (similar to A or B elements in chick-a-dee

250 calls), 5) short D elements, v) chirp call (elements similar to C elements in chickadee 
251 calls), vi) tonal call (similar to blue tit song). b) Great tits: i) jar/rattle call with 1)

252 intro element (similar to chickadee A or B elements) and 2) jar/rattle elements, ii)

253 chirp call, ix) D call, x) tonal call. c) Coal tits: i) bowl element, ii) chirp elements

254 (with peak elements), iii) dot elements, iv) hook elements, v) mound elements, vi) mt

255 elements, vii) peak elements, viii) s-dot element, ix), s elements, x) squeak elements,

256 xi) slide elements. d) Crested tits: i) normal trill call, ii) frequency-modulated trill

257 call, iii) tonal call. e) Marsh tits: i-iii) dä/D or complete calls with 1) dä/D elements,

258 2) full whole tonal element, 3) peak whole tonal element, 4) broken whole tonal

259 element, iv) ptew call. f) Willow tits: i) tää-tää call, ii) si-tää-tää call, with 1) si intro

260 element and 2) tää/D element, iii) zizi call. All spectrograms are scaled to one

261 another. For some call names we used new phonetic terminology, while for others call

262 names came from other sources: all species: (J. P. Hailman, 1989), marsh \& willow

263 tits: (Haftorn, 1993), (Japanese) great tit: (Suzuki, 2014). 


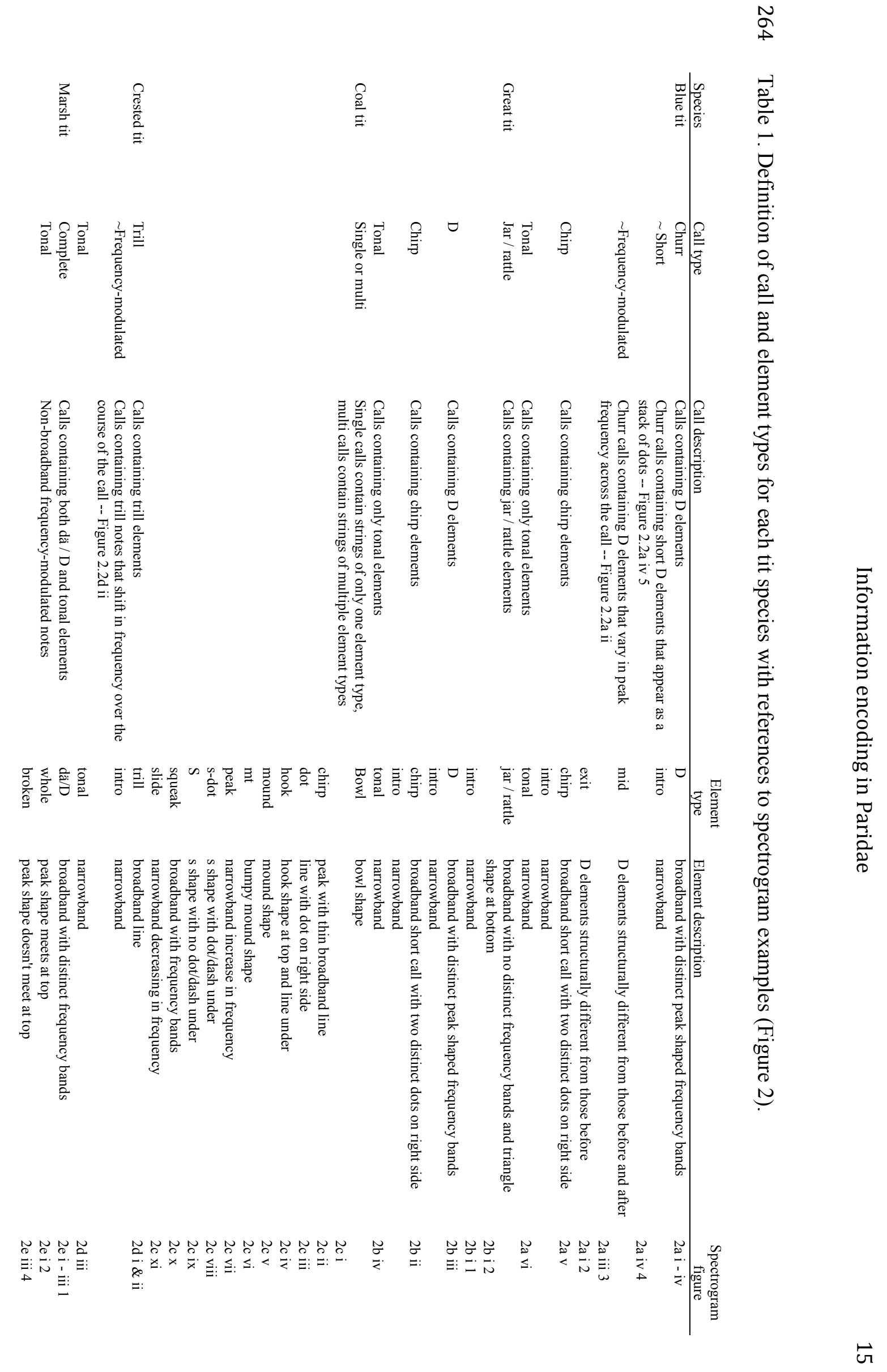




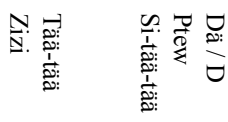

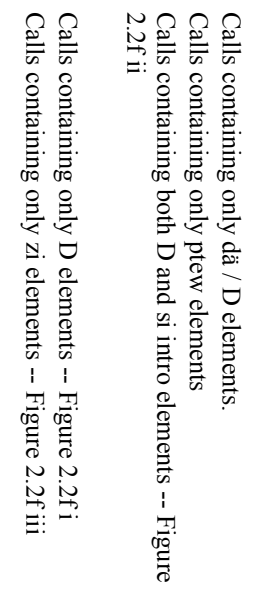

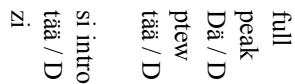
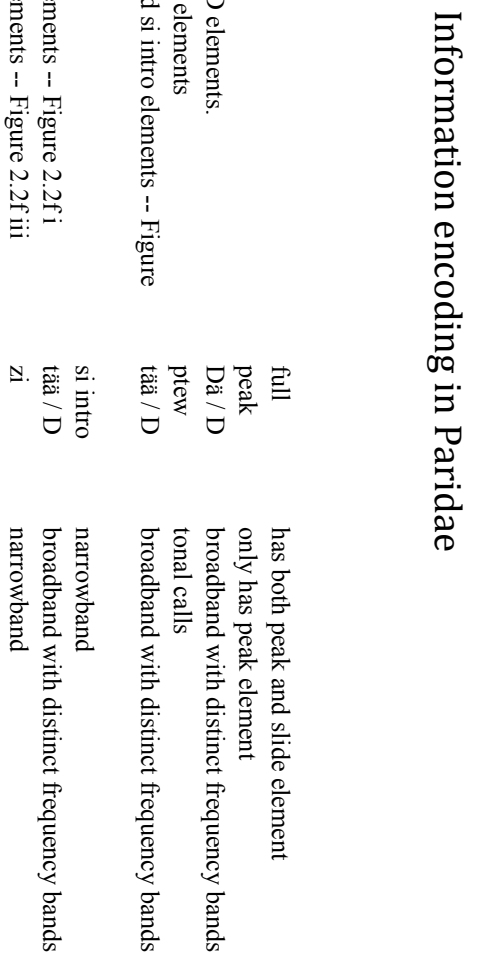

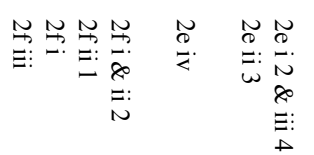


265 Statistical analysis

266 Effect of predator threat on calling behaviour

267 To test how UK tit species encode information about predator threat in their mobbing

268 calls, we focused on the four ways in which the other Parids encode information: 1)

269 call rate (calls/individual/minute), 2) total number of elements in a call (henceforth

270 'element number'; or in the case of call types that are composed of different element

271 types, the number of each element type), 3) proportion of all calls produced during a

272 mobbing event that contained particular note types during a mobbing event

273 (henceforth 'proportion'), and 4) the number of mobbing events in which birds

274 produced a particular call type divided by the total number of mobbing events

275 (henceforth 'propensity'; Baker \& Becker, 2002; Bartmess-LeVasseur et al., 2010;

276 Ficken, Hailman, \& Hailman, 1994; Hetrick \& Sieving, 2011; Soard \& Ritchison,

277 2009; Templeton et al., 2005).

278

279 To determine whether the birds used any of these ways of encoding information, we 280 generated linear mixed models or generalized linear mixed models with a Gaussian or

281 binomial error structure respectively depending on the distribution and type

282 (continuous or binomial) of the data. We constructed these models for each species

283 separately as they appeared to differ in their combinations of different call and note

284 types (Figure 2), and as each species had a range of call/note types, we tested if each

285 species employed the encoding mechanisms for each call/note type to differentiate

286 between different threat predators.

287

288 We used these statistical models to test if the bird changed a specific call/note type in 289 response to different predator threat levels for each of the four ways of encoding 
290 information. Our response variable was the way information was encoded for each

291 call/note type described above, and our fixed effects were the predator threat level and

292 three variables that accounted for the experimental design: the mount presentation

293 order, the mount exemplar, and the number of conspecifics present. To control for

294 between-feeder variation we included date and geographic region as random effects.

295 We also included a nested term 'calls per trial' that accounted for the number of calls

296 (each trial at each location had varying numbers of calls produced by each species) at

297 each feeder location during each trial. This term helped to minimize pseudoreplication

298 of calls. We transformed the data using a log or boxcox transform for any response

299 variable with non-normal residuals. For the binomial models where all calls of one of

300 the levels of stimulus:order or stimulus:mount exemplar consisted of all 1 or 0 , the

301 models could not converge, so we ran these models as linear mixed models. We ran

302 type III Wald Chi-square tests to check for significant effects of threat level for each

303 call type for each way of information encoding for all species (Table 1). For models

304 where threat level had a significant effect, we tested if the effect was different for

305 different predator threats by running a planned comparison between buzzard and

306 sparrowhawk by re-ordering stimulus levels and re-running the model (Table 1).

307 Generalized linear mixed models were fit by maximum likelihood using the Laplace

308 approximation, while linear mixed models were fit using REML and t-tests used

309 Satterthwaite approximations to generate degrees of freedom. This allowed us to test

310 what call/note types each species used to differentiate between predator threats, and

311 what information encoding mechanisms each species used. While the chance of

312 committing a type I error is higher when multiple tests are being performed, we did

313 not apply a correction such as a Bonferroni correction as we, like others, felt that the

314 chance of committing type II errors sufficiently high that biologically meaningful 
315 patterns would have been obscured (Feise, 2002; Perneger, 1998; Rothman, 1990).

316 Instead, to help assess the robustness of our results, we calculated both marginal and

317 conditional $\mathrm{R}^{2}$ values specific for linear and generalized linear mixed models

318 (Nakagawa \& Schielzeth, 2012) for the overall models (Table 2) and 95\% confidence

319 intervals for model estimates (Table 3) We conducted all statistical analyses in R

320 v3.1.2 (R Core Team, 2014), using the lme4 (Bates, Maechler, Bolker, \& Walker,

321 2014) package. In our results the ways of encoding information about predator threat

322 are as follows: 1) call rates are reported as calls/individual/minute, 2) element number

323 values as the number of elements/call, 3) all proportions as the number of calls that

324 were of a call type/total number of calls or the number of calls containing that element

325 type/total number of calls that can contain that element type (e.g. as within great tit

$326 \mathrm{jar} /$ rattle call types some calls have introductory elements, we calculated the

327 proportion of calls that contain introductory elements by dividing the number of calls

328 rattle/jar calls with introductory elements by the total number of rattle/jar calls; Figure

329 2, Table 1), and 4) propensities as the number of mobbing events where the call or

330 element type occurred/ total number of mobbing events.

332 Effect of phylogeny on calling behaviour

333 To determine if phylogeny explained the pattern of ways encoding information across

334 the species tested, we looked for phylogenetic signal using Pagel's lambda

335 (Freckleton, Harvey, \& Pagel, 2002; Pagel, 1999). We calculated Pagel's lambda for

336 a tree with correct branch lengths, and one that had been collapsed into a large

337 polytomy (no phylogenetic signal) and then compared the maximum likelihood of

338 both lambdas using a maximum likelihood test. However, as many of the measures of

339 phylogenetic signal are not as reliable with trees under 20 species (Freckleton, 
340 Harvey, \& Pagel, 2002; Münkemüller et al., 2012; Pagel, 1999) we are cautious about 341 the results of these tests.

Effect of ecology on behaviour

344 To determine if ecology explained the pattern of ways of encoding information across

345 the species, we collected ecological information from the published literature

346 (Alatalo, 1981; Cramp, 1993; Deadman, 2014; Ekman, 1989; Fisher, 1982; Gimm,

347 1960; Morse, 1978; Perrins, 1979) on foraging niche, dominance, and gregariousness

348 for each species and included them as explanatory variables in our statistical models.

349 We chose these variables because each has been suggested as having an effect on 350 anti-predatory behaviour (Goodale et al., 2010).

352 Foraging niche, as measured by the height and distance from a tree trunk, influences 353 the exposure and vulnerability of a species when foraging and can therefore affect the 354 vulnerability of a species to predation. For example a species that forages high up in 355 trees or on insects in the air spend more time scanning the sky and may be more likely 356 to see, and respond to, an aerial predator while a species that forages near to, or on, 357 the ground may not (Goodale et al., 2010; Goodale \& Kotagama, 2005a; Lima, 1993;

358 Magrath et al., 2014). Greater racket-tailed drongos, Dicrurus paradiseus (Goodale \& 359 Kotagama, 2005a) and red-cap moustached tamarins, Saguinus mystax pileatus 360 (Peres, 1993) for example, both forage high up off the ground (sallying and upper 361 canopy respectively) and are the species in their mixed-species groups that are most 362 likely to detect aerial predators. 
364 Interspecific dominance, as measured by shifts in foraging niche in the presence and 365 absence of heterospecifics (Alatalo, 1981; Perrins, 1979), can affect the likelihood of 366 a species to eavesdrop on, rather than produce information about predator threats.

367 Because a dominant individual is in a better position to eavesdrop on information 368 provided by subordinates (Gill \& Bierema, 2013; Goodale et al., 2010), rather than to 369 produce information about predators, it has less need of a variety of ways to encode 370 information (Furrer \& Manser, 2009; Marler, 1967).

371

372 Gregariousness, measured as the average size of a conspecific winter flock, could also 373 affect the chance of seeing a predator, and therefore the propensity to produce calls, 374 and the complexity of signalling might increase with increased group size (Freeberg 375 \& Harvey, 2008; Goodale et al., 2010; Magrath et al., 2014; Manser et al., 2014).

376 Orange-billed babblers, Turdoide rsufescens (Goodale \& Kotagama, 2005b) and red377 cap moustached tamarinds (Peres, 1993) are the most abundant species in their mixed 378 species flocks and tend to spend more time scanning and respond to more potential 379 threats, respectively, than do their flock mates. Downy woodpeckers, Picoides 380 pubescens (Sullivan, 1985) and yellow mongoose, Cynictis penicillata (le Roux, 381 Cherry, \& Manser, 2008) tend to produce alarm calls only when heterospecifics are 382 present, while the anti-predator vocal repertoire size of mongoose species, 383 Herpestidae, increases with group size and social complexity (Manser et al., 2014). 384

385 To determine if there was a correlation between each species' ecology and the ways 386 in which they encoded predator threat information we ran four generalized linear 387 models with binomial error structure including the ways of encoding information as 388 our response variable. We ran an analysis of deviance on the model to test for 
389 significant effects of the three ecological variables - foraging niche, dominance, and 390 gregariousness - on the ways that each species encoded information about predator 391 threat.

\section{RESULTS}

Blue tits

Blue tits used all four ways of encoding information to differentiate between predators and non-threats and to differentiate between different levels of threat (Table controls, more to buzzards, and the most to sparrowhawks (mean \pm standard error, conditional $\mathrm{R}_{\mathrm{GLMM}}^{2}$; control: $1.06 \pm 0.24$; buzzard: $2.12 \pm 0.37$; sparrowhawk: $6.21 \pm$ $0.73 ; \mathrm{R}_{\text {GLMM }}^{2}=0.613$ ). Blue tits increased the total number of elements and D notes as threat increased, and decreased the number of mid notes to buzzards compared to

404 the other stimuli (elements: control $8.69 \pm 0.21$, buzzard $10.38 \pm 0.25$, sparrowhawk $40513.01 \pm 0.17, \mathrm{R}_{\mathrm{GLMM}}^{2}=0.305 ; \mathrm{D}$ : control $9.26 \pm 0.28$, buzzard $11.53 \pm 0.33$, 406 sparrowhawk $14.05 \pm 0.19, \mathrm{R}^{2}{ }_{\mathrm{GLMM}}=0.699$; mid: control $2.57 \pm 0.30$, buzzard $1.76 \pm$ 4070.17 , sparrowhawk $3.22 \pm 0.19, \mathrm{R}_{\mathrm{GLMM}}^{2}=0.478$; Table 2). Blue tits produced a 408 smaller proportion of the churr mobbing calls that include exit notes compared to 409 either controls or sparrowhawks than to buzzards, and a smaller proportion of calls 410 with chirp notes to sparrowhawks than to controls or buzzards (exit: control $0.21 \pm$ 4110.02 , buzzard $0.16 \pm 0.01$, sparrowhawk $0.21 \pm 0.01, \mathrm{R}_{\mathrm{GLMM}}^{2}=0.469$; chirp: control $4120.31 \pm 0.02$; buzzard $0.32 \pm 0.02$, sparrowhawk $0.10 \pm 0.01, \mathrm{R}_{\mathrm{GLMM}}^{2}=0.668 ;$ Table 413 2). Blue tits also increase the proportion of tonal notes as threat increases (control 
$4140.12 \pm 0.01$, buzzard $0.15 \pm 0.02$, sparrowhawk $\left.0.20 \pm 0.01, \mathrm{R}_{\mathrm{GLMM}}^{2}=0.533\right)$. Blue 415 tits increased their propensity to produce mid, exit, tonal, frequency modulated, and 416 short notes to high-threat predators compared to low-threat predators or controls (mid:

417 control $0.07 \pm 0.04$, buzzard $0.15 \pm 0.05$, sparrowhawk $0.44 \pm 0.08, \mathrm{R}_{\text {GLMM }}^{2}=0.488$;

418 exit: control $0.40 \pm 0.08$, buzzard $0.40 \pm 0.07$, sparrowhawk $0.84 \pm 0.06, \mathrm{R}_{\mathrm{GLMM}}^{2}=$ 4190.251 ; tonal: control $0.24 \pm 0.07$, buzzard $0.40 \pm 0.07$, sparrowhawk $0.65 \pm 0.07$, $420 \mathrm{R}_{\mathrm{GLMM}}^{2}=0.247$; frequency modulated: control $0.31 \pm 0.07$, buzzard $0.32 \pm 0.07$, 421 sparrowhawk $0.67 \pm 0.07, \mathrm{R}^{2}{ }_{\mathrm{GLMM}}=0.607$; short: $0.44 \pm 0.08$, exit $0.84 \pm 0.06$, 422 sparrowhawk $0.95 \pm 0.03, \mathrm{R}_{\text {GLMM }}^{2}=0.370$; Table 2).

\section{Great tits}

425

426 To differentiate one or both predators from the control great tits used three ways of 427 encoding information: call rate, proportion, and propensity. However, they only used 428 call rate to differentiate between high and low threat predators (Table 2; Figure 3). 429 Great tits had a higher call rate in response to high threats compared to controls and 430 buzzards (control: $1.00 \pm 0.21$, buzzard: $3.27 \pm 0.61$, sparrowhawk: $8.54 \pm 1.17$, $431 \mathrm{R}_{\text {GLMM }}^{2}=0.465$; Table 2). They decreased the proportion of calls that contained chirp 432 elements and increased the propensity to produce jar/rattle calls during a mobbing 433 event to predators compared to controls (chirp proportion: control $0.14 \pm 0.21$, 434 buzzard $0.02 \pm 0.01$, sparrowhawk $0.009 \pm 0.002, \mathrm{R}_{\mathrm{GLMM}}^{2}=0.578$; jar/rattle 435 propensity: control $0.68 \pm 0.08$, buzzard $0.81 \pm 0.06$, sparrowhawk $0.95 \pm 0.03$, $436 \mathrm{R}_{\text {GLMM }}^{2}=0.271$; Table 2). 
440 Coal tits encoded information in three ways to differentiate between controls and 441 predator threats: call rate, element number, and propensity (Table 2). Coal tits only 442 used element number, however, to differentiate between predators of varying threat 443 levels in their mobbing calls (Table 2; Figure 3). Coal tits increased their call rate as 444 threat increased (control: $0.45 \pm 0.11$, buzzard: $2.53 \pm 0.56$, sparrowhawk: $5.25 \pm$ $\left.4451.00, \mathrm{R}_{\mathrm{GLMM}}^{2}=0.347\right)$. Coal tits produced more hook and mt elements to buzzards 446 than either controls or sparrowhawks (hook: control $1.69 \pm 0.16$, buzzard $3.91 \pm 0.23$, 447 sparrowhawk $3.62 \pm 0.30, \mathrm{R}_{\mathrm{GLMM}}^{2}=0.490, \mathrm{mt}$ : control $1.43 \pm 0.14$, buzzard $2.97 \pm$ 4480.38 , sparrowhawk $1.47 \pm 0.12, \mathrm{R}_{\mathrm{GLMM}}^{2}=0.313$; Table 2). Coal tits produced fewer 449 squeak and more mound elements to controls than to predator threats, and more s-dot 450 elements as threat increased (squeak: control $2.71 \pm 1.39$, buzzard $2.73 \pm 0.16$,

451 sparrowhawk $2.79 \pm 0.10, \mathrm{R}_{\mathrm{GLMM}}^{2}=0.198$; mound: control $2.50 \pm 0.50$, buzzard 1.93 $452 \pm 0.28$, sparrowhawk $1.77 \pm 0.14, \mathrm{R}_{\mathrm{GLMM}}^{2}=0.608$; s-dot: control $2.09 \pm 0.34$, buzzard $4533.36 \pm 0.10$, sparrowhawk $4.15 \pm 0.17, \mathrm{R}_{\mathrm{GLMM}}^{2}=0.319$; Table 2). Coal tits decreased 454 their propensity to produce mound or squeak elements in response to controls 455 compared to predatory stimuli (mound: control $0.06 \pm 0.04$, buzzard $0.29 \pm 0.08$, 456 sparrowhawk $0.51 \pm 0.08, \mathrm{R}_{\mathrm{GLMM}}^{2}=0.300$; squeak: control $0.14 \pm 0.01=6$, buzzard $457 \quad 0.47 \pm 0.09$, sparrowhawk $0.63 \pm 0.08, \mathrm{R}_{\mathrm{GLMM}}^{2}=0.473$; Table 2).

$459 \quad$ Crested tits

460

461 Crested tits differentiated one or both predators from the control in three ways: call 462 rate, proportion, and propensity. However, they only used proportion and propensity 463 to differentiate between different threat predators (Table 2; Figure 3). They increased 
464 their call rate as threat increased, produced a higher proportion of frequency

465 modulated calls, and a lower propensity to produce tonal notes in response to

466 buzzards compared to controls and sparrowhawks (rate: control $11.71 \pm 4.33$, buzzard

$467 \quad 14.92 \pm 3.38$, sparrowhawk $16.32 \pm 2.30, \mathrm{R}_{\mathrm{GLMM}}^{2}=0.479$; frequency modulated

468 proportion: control $0.61 \pm 0.02$, buzzard $0.75 \pm 0.01$, sparrowhawk $0.73 \pm 0.01$,

$469 \mathrm{R}_{\text {GLMM }}^{2}=0.364$; tonal propensity: control $0.21 \pm 0.11$, buzzard $0.08 \pm 0.08$,

470 sparrowhawk $0.38 \pm 0.14, \mathrm{R}^{2}{ }_{\text {GLMM }}=0.289$; Table 2; Figure 3).

471

$472 \quad$ Marsh tits

473

474 Marsh tits used all four ways of encoding information to differentiate both between

475 predators and non-threats and between predators of different threat levels (Table 2;

476 Figure 3). Marsh tits increased their call rate to predators compared to controls,

477 decreased the number of dä/D elements in response to buzzards compared to controls

478 or sparrowhawks, and decreased the proportion of full tonal notes to buzzards

479 compared to controls and sparrowhawks (rate: control: $1.24 \pm 0.35$; buzzard: $1.26 \pm$

$480 \quad 0.30$; sparrowhawk: $4.56 \pm 0.85, \mathrm{R}^{2}{ }_{\mathrm{GLMM}}=0.740$; dä/D elements: control: $0.21 \pm$

4810.11 ; buzzard: $0.08 \pm 0.08$; sparrowhawk: $0.38 \pm 0.14, \mathrm{R}_{\mathrm{GLMM}}^{2}=0.324$; proportion of

482 full tonal notes: control: $0.71 \pm 0.07$; buzzard: $0.49 \pm 0.08$; sparrowhawk: $0.53 \pm 0.03$,

$483 \mathrm{R}_{\text {GLMM }}^{2}=0.370$; Table 2). They also increased their propensity to produce peak tonal

484 elements, all tonal, and ptew calls to higher threat predators (peak tonal: control 0.33

$485 \pm 0.17$, buzzard $0.56 \pm 0.18$, sparrowhawk $0.89 \pm 0.11, \mathrm{R}_{\text {GLMM }}^{2}=0.608$; tonal: control

$4860.78 \pm 0.15$, buzzard $0.89 \pm 0.11$, sparrowhawk $1.00 \pm 0.00, \mathrm{R}^{2}{ }_{\mathrm{GLMM}}=0.398$; ptew:

487 control $0.78 \pm 0.05$, buzzard $0.89 \pm 0.11$, sparrowhawk $1.00 \pm 0.00, \mathrm{R}_{\mathrm{GLMM}}^{2}=0.398$;

488 Table 2). 
$490 \quad$ Willow tits

491

492 Willow tits varied several call features between the control and predator treatments 493 but did not differentiate between predators of different threat levels (Table 2; Figure

4943 ). Willow tits increased their call rate in response to predators (mean \pm standard 495 error; buzzard: $1.72 \pm 0.42$; sparrowhawk; $2.04 \pm 0.25, \mathrm{R}_{\mathrm{GLMM}}^{2}>0.999$ ) compared to 496 controls (control: $0.71 \pm 0.28$; Table 2). Willow tits also increased the number of total 497 elements and decreased the number of si intro elements as predator threat increased 498 (elements: control $2.40 \pm 0.22$, buzzard $2.86 \pm 0.14$, sparrowhawk, $3.59 \pm 0.12$, $499 \mathrm{R}_{\mathrm{GLMM}}^{2}=0.201$; si intro: control $2.00 \pm 0.49$, buzzard $2.51 \pm 0.19$, sparrowhawk 2.83 $500 \pm 0.14, \mathrm{R}_{\text {GLMM }}^{2}=0.207$; Table 2).

502 For all species, we observed some order and mount exemplar effects in the statistical 503 models, but as none of these effects were consistent across call types, ways of 504 encoding information, stimulus species, or responding tit species, they are not 505 included in our results. 

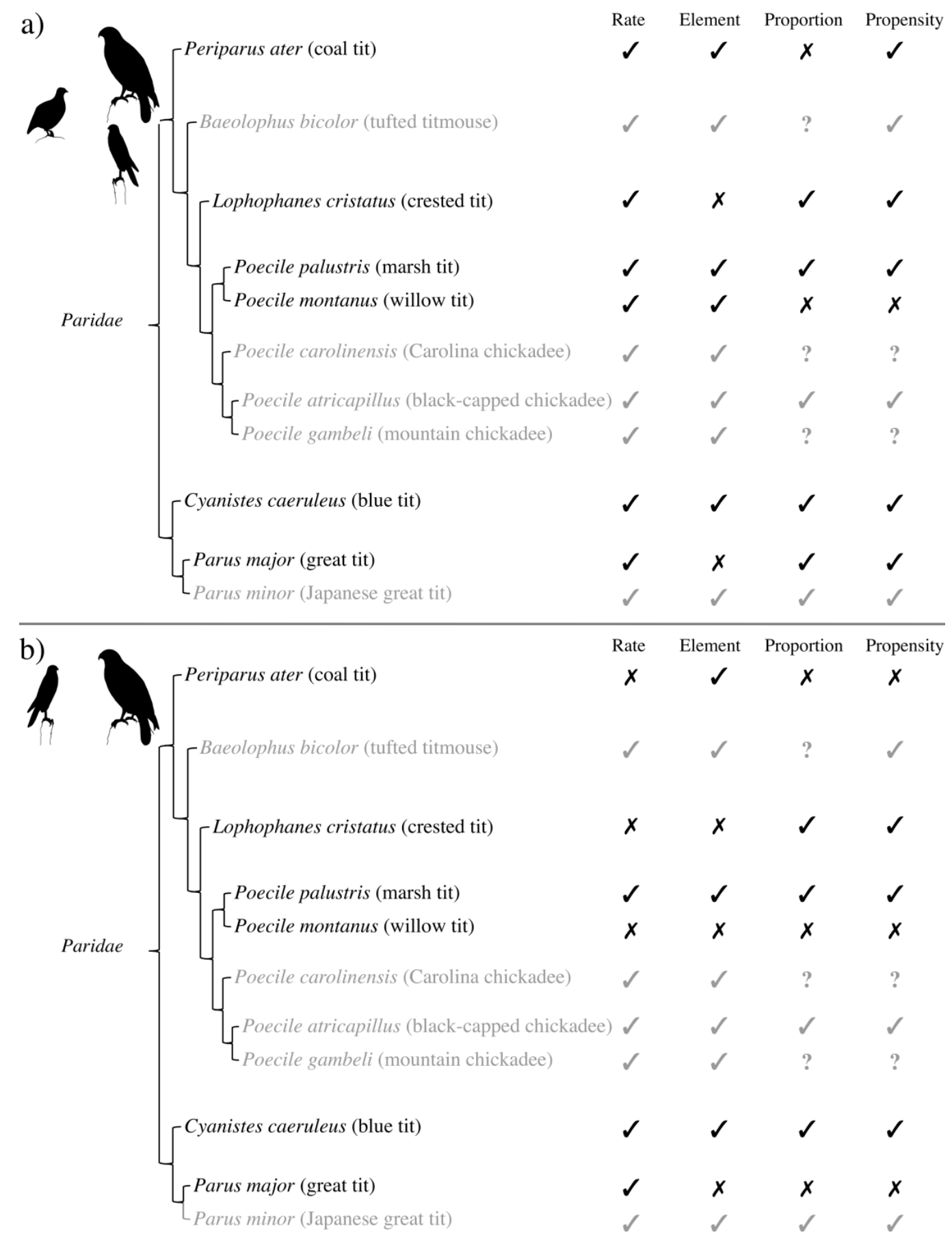

507 Figure 3. The four ways in which each of the previously studied Paridae encode

508 information differentiating a) predators (sparrowhawk and buzzard) from non-

509 predators (partridge) and b) high (sparrowhawk) from low (buzzard) threat predators.

510 Rate: call rate, Element: number of elements in a call, Proportion: the proportion of

511 call types used within a mobbing event, Propensity: the propensity to produce call 
512 types across mobbing events. Light grey text indicates those species tested in previous

513 studies, question marks indicate encoding mechanisms not previously tested, and Xs

514 show mechanisms that are not used. Phylogeny information was based on (Johansson

515 et al., 2013). Published data derived from: black-capped chickadee: (Baker \& Becker,

516 2002; Billings et al., 2015; Clemmons \& Lambrechts, 1992; Templeton et al., 2005),

517 tufted titmouse: (Bartmess-LeVasseur et al., 2010; Courter \& Ritchison, 2010;

518 Hetrick \& Sieving, 2011; Sieving et al., 2010), Carolina chickadee: (Bartmess-

519 LeVasseur et al., 2010; Hetrick \& Sieving, 2011; Soard \& Ritchison, 2009), Mexican

520 chickadee: (Billings et al., 2015), Japanese great tit: (Suzuki, 2012; 2014; Suzuki \&

521 Ueda, 2013).

522 


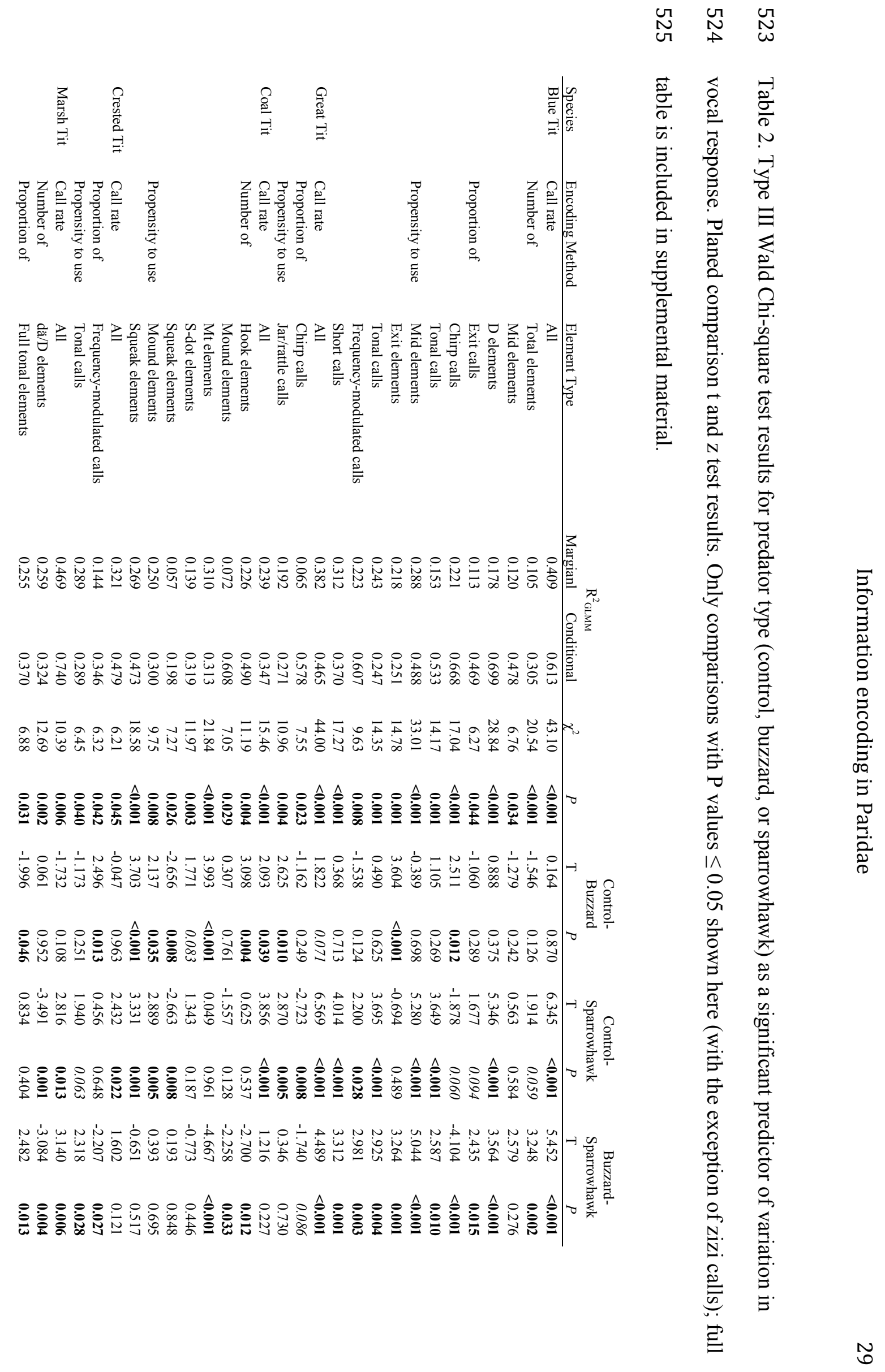


ส

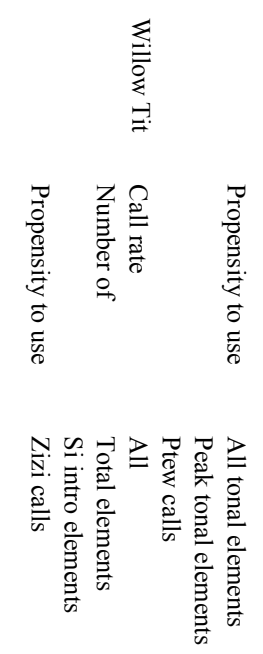

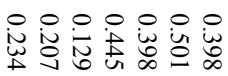

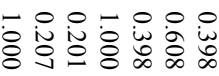

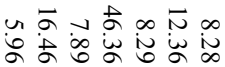

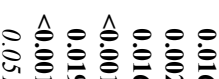

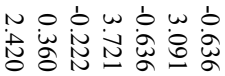

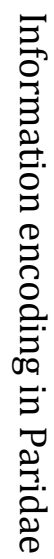

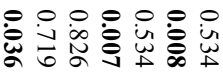

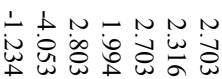

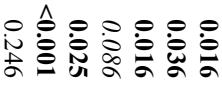

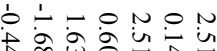

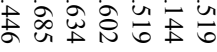

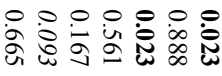


527 Table 3. Model estimates and 95\% confidence intervals for linear and generalized

528 linear mixed models determining if predatory type (control, buzzard, or sparrowhawk)

529 had a significant effect on the variation in vocal response of UK tit species (Table 2).

\begin{tabular}{|c|c|c|c|c|c|c|}
\hline \multirow[b]{2}{*}{ Species } & \multirow[b]{2}{*}{ Encoding Method } & \multirow[b]{2}{*}{ Element Type } & \multirow[b]{2}{*}{ Stimulus } & \multirow[b]{2}{*}{$\begin{array}{l}\text { model } \\
\text { estimate }\end{array}$} & \multicolumn{2}{|c|}{$95 \%$ Confidence interval } \\
\hline & & & & & lower & upper \\
\hline \multirow[t]{36}{*}{ Blue Tit } & Call rate & All & Control & 4.076 & -2.090 & 4.468 \\
\hline & & & Buzzard & 1.189 & -2.470 & 10.623 \\
\hline & & & Sparrowhawk & 8.971 & 0.834 & 17.109 \\
\hline & Number of & Total elements & Control & 9.620 & 6.802 & 12.438 \\
\hline & & & Buzzard & 7.310 & 1.563 & 13.057 \\
\hline & & & Sparrowhawk & 12.463 & 6.734 & 18.191 \\
\hline & Number of & Mid elements & Control & 3.716 & 1.439 & 5.993 \\
\hline & & & Buzzard & 2.235 & -2.311 & 6.782 \\
\hline & & & Sparrowhawk & 4.241 & 0.138 & 8.344 \\
\hline & Number of & D elements & Control & 1.745 & 1.597 & 1.894 \\
\hline & & & Buzzard & 1.810 & 1.518 & 2.102 \\
\hline & & & Sparrowhawk & 2.121 & 1.835 & 2.407 \\
\hline & Proportion of & Exit calls & Control & -1.822 & -3.016 & -0.628 \\
\hline & & & Buzzard & -2.705 & -5.532 & 0.122 \\
\hline & & & Sparrowhawk & -0.606 & -3.221 & 2.009 \\
\hline & Proportion of & Chirp calls & Control & -2.933 & -4.600 & -1.266 \\
\hline & & & Buzzard & -0.376 & -4.039 & 3.286 \\
\hline & & & Sparrowhawk & -4.924 & -8.668 & -1.179 \\
\hline & Proportion of & Tonal calls & Control & -4.670 & -6.436 & -2.903 \\
\hline & & & Buzzard & -3.759 & -7.140 & -0.379 \\
\hline & & & Sparrowhawk & -1.672 & -5.048 & 1.704 \\
\hline & Propensity to use & Mid elements & Control & 0.034 & -0.177 & 0.244 \\
\hline & & & Buzzard & -0.017 & -0.486 & 0.451 \\
\hline & & & Sparrowhawk & 0.779 & 0.292 & 1.267 \\
\hline & Propensity to use & Exit elements & Control & 0.133 & 0.046 & 0.569 \\
\hline & & & Buzzard & 0.134 & -0.286 & 0.903 \\
\hline & & & Sparrowhawk & 0.792 & 0.346 & 1.585 \\
\hline & Propensity to use & Tonal calls & Control & -0.009 & -0.250 & 0.232 \\
\hline & & & Buzzard & 0.074 & -0.500 & 0.648 \\
\hline & & & Sparrowhawk & 0.666 & 0.067 & 1.264 \\
\hline & Propensity to use & Frequency-modulated calls & Control & 0.691 & 0.125 & 0.972 \\
\hline & & & Buzzard & 0.793 & 0.132 & 1.617 \\
\hline & & & Sparrowhawk & 1.613 & 0.692 & 1.963 \\
\hline & Propensity to use & Short calls & Control & 0.288 & 0.069 & 0.506 \\
\hline & & & Buzzard & 0.344 & -0.175 & 0.864 \\
\hline & & & Sparrowhawk & 0.948 & 0.407 & 1.490 \\
\hline \multirow[t]{9}{*}{ Great Tit } & Call rate & All & Control & 2.479 & -0.433 & 5.391 \\
\hline & & & Buzzard & 6.122 & -0.709 & 12.953 \\
\hline & & & Sparrowhawk & 16.091 & 9.117 & 23.064 \\
\hline & Proportion of & Chirp calls & Control & 0.131 & 0.028 & 0.235 \\
\hline & & & Buzzard & 0.200 & -0.156 & 0.282 \\
\hline & & & Sparrowhawk & 0.301 & -0.264 & 0.187 \\
\hline & Propensity to use & Jar/rattle calls & Control & 0.438 & 0.206 & 0.670 \\
\hline & & & Buzzard & 0.849 & 0.311 & 1.388 \\
\hline & & & Sparrowhawk & 0.911 & 0.356 & 1.466 \\
\hline \multirow[t]{4}{*}{ Coal Tit } & Call rate & All & Control & 0.431 & -2.258 & 3.120 \\
\hline & & & Buzzard & 4.633 & -1.991 & 11.257 \\
\hline & & & Sparrowhawk & 7.247 & 1.094 & 13.400 \\
\hline & Number of & Hook elements & Control & 1.737 & 1.055 & 2.862 \\
\hline
\end{tabular}




\begin{tabular}{|c|c|c|c|c|c|c|}
\hline & & & Buzzard & 4.608 & 2.528 & 8.455 \\
\hline & & & Sparrowhawk & 2.959 & 1.706 & 5.153 \\
\hline & Number of & Mound elements & Control & 2.707 & 0.960 & 7.627 \\
\hline & & & Buzzard & 3.905 & 1.338 & 11.435 \\
\hline & & & Sparrowhawk & 3.192 & 1.156 & 8.832 \\
\hline & Number of & Mt elements & Control & 1.607 & 1.035 & 2.495 \\
\hline & & & Buzzard & 7.049 & 3.404 & 14.997 \\
\hline & & & Sparrowhawk & 2.619 & 1.666 & 4.116 \\
\hline & Number of & S-dot elements & Control & 2.315 & 1.293 & 4.148 \\
\hline & & & Buzzard & 4.258 & 2.224 & 4.395 \\
\hline & & & Sparrowhawk & 3.853 & 2.113 & 4.495 \\
\hline & Number of & Squeak elements & Control & 10.472 & 3.042 & 36.042 \\
\hline & & & Buzzard & 10.647 & 3.091 & 36.676 \\
\hline & & & Sparrowhawk & 10.655 & 3.095 & 36.681 \\
\hline & Propensity to use & Mound elements & Control & -0.057 & -0.287 & 0.173 \\
\hline & & & Buzzard & 0.368 & -0.251 & 0.988 \\
\hline & & & Sparrowhawk & 0.452 & -0.123 & 1.027 \\
\hline & Propensity to use & Squeak elements & Control & 0.036 & -0.209 & 0.281 \\
\hline & & & Buzzard & 0.801 & 0.151 & 1.451 \\
\hline & & & Sparrowhawk & 0.654 & 0.046 & 1.262 \\
\hline Crested Tit & Call rate & All & Control & 10.084 & -5.110 & 25.277 \\
\hline & & & Buzzard & 9.511 & -29.763 & 48.786 \\
\hline & & & Sparrowhawk & 31.261 & -0.998 & 63.519 \\
\hline & Proportion of & Frequency-modulated calls & Control & -0.430 & -2.066 & 1.205 \\
\hline & & & Buzzard & 2.832 & -1.365 & 7.029 \\
\hline & & & Sparrowhawk & -0.057 & -3.297 & 3.183 \\
\hline & Propensity to use & Tonal calls & Control & 0.186 & -0.309 & 0.680 \\
\hline & & & Buzzard & -0.309 & -1.632 & 1.013 \\
\hline & & & Sparrowhawk & 0.751 & -0.315 & 1.817 \\
\hline Marsh Tit & Call rate & All & Control & 4.076 & -0.043 & 8.196 \\
\hline & & & Buzzard & 1.189 & -6.198 & 8.576 \\
\hline & & & Sparrowhawk & 8.971 & 1.444 & 16.498 \\
\hline & Number of & Dä/D elements & Control & -7.905 & -17.199 & 1.389 \\
\hline & & & Buzzard & -7.717 & -23.088 & 7.653 \\
\hline & & & Sparrowhawk & -21.884 & -39.026 & -4.741 \\
\hline & Proportion of & Full intro elements & Control & 0.997 & 0.849 & 1.000 \\
\hline & & & Buzzard & 1.029 & 0.850 & 1.484 \\
\hline & & & Sparrowhawk & 1.821 & 0.960 & 1.994 \\
\hline & Propensity to use & All tonal elements & Control & 0.821 & 0.145 & 1.498 \\
\hline & & & Buzzard & 0.643 & -0.584 & 1.870 \\
\hline & & & Sparrowhawk & 1.571 & 0.351 & 2.792 \\
\hline & Propensity to use & Peak tonal elements & Control & -0.827 & -1.761 & 0.107 \\
\hline & & & Buzzard & 0.416 & -1.306 & 2.137 \\
\hline & & & Sparrowhawk & 0.505 & -1.556 & 2.567 \\
\hline & Propensity to use & Ptew calls & Control & 0.821 & 0.145 & 1.498 \\
\hline & & & Buzzard & 0.643 & -0.584 & 1.870 \\
\hline & & & Sparrowhawk & 1.571 & 0.351 & 2.792 \\
\hline Willow Tit & Call rate & All & Control & 1.335 & -0.194 & 2.864 \\
\hline & & & Buzzard & 3.045 & 0.615 & 5.475 \\
\hline & & & Sparrowhawk & 2.817 & -0.169 & 5.804 \\
\hline & Number of & Total elements & Control & 4.012 & 1.738 & 9.261 \\
\hline & & & Buzzard & 4.953 & 2.289 & 10.869 \\
\hline & & & Sparrowhawk & 6.649 & 3.077 & 14.456 \\
\hline & Number of & Si intro elements & Control & 0.745 & 0.555 & 0.936 \\
\hline & & & Buzzard & 0.772 & 0.437 & 1.108 \\
\hline & & & Sparrowhawk & 0.563 & 0.285 & 0.842 \\
\hline & Propensity to use & Zizi calls & Control & -0.065 & -1.300 & 1.169 \\
\hline & & & Buzzard & 1.008 & -1.096 & 3.111 \\
\hline & & & Sparrowhawk & -0.959 & -3.613 & 1.695 \\
\hline
\end{tabular}




\section{Phylogeny AND ECOLOGY}

533 Phylogenetic signal did not explain which species used which ways of encoding

534 information about predator threat in their mobbing calls (rate: $\chi^{2}{ }_{1}=-0.03, P=1$;

535 number of elements: $\chi^{2}{ }_{1}=-1.37, P=1$; proportion: $\chi^{2}{ }_{1}=-6.36, P=1$; propensity: $\chi^{2}{ }_{1}$

$536=-1.30, P=1)$. Ecology also did not explain variation in which species used each

537 method of encoding information about predator threat in their mobbing calls (rate:

538 foraging niche $\mathrm{F}(2)=1.05, P=0.431$, dominance $\mathrm{F}(2)=6.59, P=0.054$,

539 gregariousness $\mathrm{F}(2)=2.77, P=0.176$; number of elements: foraging niche $\mathrm{F}(2)=$

$5402.66, P=0.184$, dominance $\mathrm{F}(2)=1.91, P=0.262$, gregariousness $\mathrm{F}(2)=1.05, P=$

5410.431 ; proportion: foraging niche $\mathrm{F}(2)=0.26, P=0.810$, dominance $\mathrm{F}(2)=1.39, P=$

5420.515 , gregariousness $\mathrm{F}(2)<0.001, P>0.999$; propensity: foraging niche $\mathrm{F}(2)=0.52$,

$543 P=0.657$, dominance $\mathrm{F}(2)=2.77, P=0.265$, gregariousness $\mathrm{F}(2)<0.001, P>$

544 0.999). 


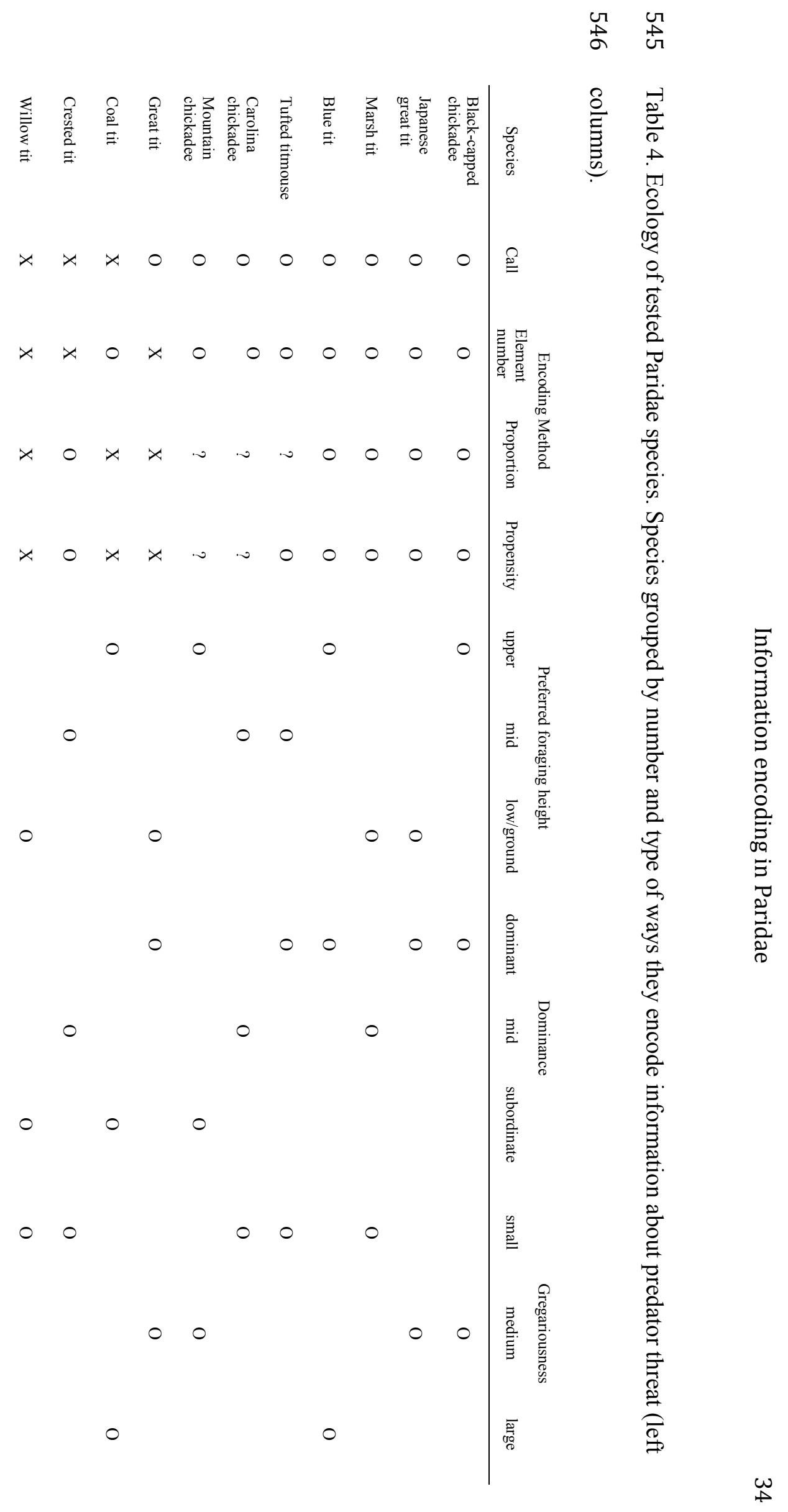


547

548

549 We found that the UK tit species varied in both the types and degree to which they 550 551 552 553

554 predators. These results are not consistent with the presumption that all Paridae use

555 the same mechanisms to encode similar information about predators.

557 Variation across species in signalling strategy could potentially be explained by

558 relatedness: those species more closely related should be more similar in terms of the

559 ways of encoding information they use to encode information about predators. The

560 presence or absence of alarm calling as a behaviour in rodents appears to be well

561 explained by phylogeny, though this says nothing concerning the specific ways of

562 encoding information in these calls (Shelly \& Blumstein, 2005). We found no

563 correlation between the Parid phylogeny and the pattern of ways of encoding

564 information. Additionally, we could find no patterns in the ways the traits mapped

565 onto the phylogeny that would explain the ways of encoding information used by the

566 species we tested. Marsh tits, for example, encode information in the same ways as do

567 blue tits, one of their more distant relatives, while they share only half of the ways of

568 communicating the presence of a predator and none of the same ways of

569 communicating the threat of a predator, with congeneric willow tits. Relatedness

570 similarly fails to explain the variation in the number and mechanisms across the rest

571 of the phylogeny. These patterns are similar to those found in marmots, which also 
572 vary the ways in which they encode information about predators based on a factor

573 other than phylogenetic relatedness (Blumstein, 2007).

574

575 If relatedness does not explain the number or ways of encoding information used by

576 UK tits, aspects of their natural history might. Some species may be pre-disposed

577 through their ecology to be better equipped to notice and respond to predators, and

578 these species therefore may use a greater variety of ways of communicating that

579 information (Goodale, Beauchamp, Magrath, Nieh, \& Ruxton, 2010). However, our

580 tests indicated no correlations between any of the three ecological variables we

581 examined and the ways in which the different species encoded predator threat

582 information. If foraging niche explained ways of encoding information then we would

583 have expected that outer/upper canopy-foraging blue and coal tits should be more

584 similar in the ways in which they encode information, relative to species that forage in

585 locations with limited visibility (lower trunk foraging: marsh, willow, and great tits)

586 as these species are less exposed to predatory raptors (Gibb, 1960; Morse, 1978;

587 Nakamura, 1970; Perrins, 1979). Blue and marsh tits are, however, more similar in

588 the ways in which they respond to predators (both presence and threat) than are blue

589 and coal tits. Foraging niche, at least, does not seem to be an especially useful

590 explanation for the variation in the ways of encoding information. Similarly, we

591 would have expected species that travel in larger winter flocks, such as blue, great,

592 and coal tits, to use more ways of encoding information relative to those less

593 gregarious species (crested, marsh, and willow tits; Deadman, 2014; Ekman, 1979;

594 1989; Fisher, 1982; Morse, 1978). As the more gregarious tit species are, however, no

595 more likely to use more ways of encoding information than the less gregarious

596 species, gregariousness during winter also is not a good explanation for the variation 
597 we see . Finally, if interspecific dominance influenced ways of encoding information

598 we would have expected the more dominant great and blue tits to use more similar

599 ways of encoding information. However blue and great tits were no more similar in

600 the ways they encode information than are the more subordinate coal or willow tits

601 (Alatalo, 1981; Cramp, 1993; Perrins, 2012). Given that neither phylogeny or any of

602 the more plausible natural history traits provide an explanation for the variation in the

603 number or ways that the UK species use to encode predator information in their

604 mobbing calls, the question becomes why do these species communicate predator

605 threat with such variety?

606

607 There are two common explanations for the use of multiple ways of encoding

608 information about a single event or threat. The first is that the multiplicity is an

609 artefact of the signaller's internal state: as the animal's internal state affects a suite of

610 aspects of its vocal response via arousal, an increase in that animal's arousal (fear)

611 will result in an increase in the call rate, number of elements, or even different call

612 types (Blumstein, 2007; Blumstein \& Armitage, 1997; J. P. Hailman \& Ficken, 1996;

613 Marler, Evans, \& Hauser, 1992; Seyfarth \& Cheney, 2003). This explanation

614 presupposes that the information provided to receivers is redundant but that the

615 variety in the ways the information is provided leads to a stronger or more urgent

616 signal (Blumstein \& Armitage, 1997; Marler et al., 1992).

617

618 The second explanation is that each way of encoding information is used to

619 communicate different information about the thereat, enabling a signaller to increase

620 the amount of information it can deliver (Marler et al., 1992; Suzuki, Wheatcroft, \&

621 Griesser, 2016). Here the information, while pertaining to the same threat, is not 
622 redundant. For example, Japanese great tit mobbing calls contain different element

623 types that elicit two different types of behaviour: A, B and C notes elicit scanning

624 behaviour, while D notes elicit approach behaviour (Suzuki, 2016). In order to

625 address why related species use different ways to encode predator threat, we need to

626 establish what specific information it is that they encode (Templeton et al., 2005).

627 Redundancy does seem to explain changes in the acoustic features of the calls that

628 California ground squirrels, Spermophilus beecheyi, use to signal state of arousal

629 (Owings \& Virginia, 1978). Conversely, signallers might use different ways of

630 encoding information to encode different types of information, predatory category

631 using propensity and distance using call rate (Griesser, 2008; Suzuki et al., 2016).

632 This appears to be relatively common among primates. Blue monkeys, Cercopithecus

633 mitis stuhlmanni, for example, signal predator type using propensity of certain call

634 types, but change the rate of each call type as predator distance decreases to signal

635 increased threat (Murphy et al., 2013).

636

637 As UK tit species each use different ways to encode information in their calls, and as

638 there is no explanation for this variation in either their phylogenetic relatedness or

639 their ecology, they may provide a fruitful system for investigating how species might

640 use different ways of encoding information to encode redundant or additive

641 information. Although the information encoded in these types of vocalizations is well

642 researched, the causes of the intra- and interspecific differences remain unclear.

643 Investigating the prevalence of the multiple ways of encoding information across

644 species and by addressing the types of information that these different approaches

645 achieve may allow us to derive further evolutionary insights into variation in

646 information encoding strategies. 
647

\section{REFERENCES}

649

650 Alatalo, R. V. (1981). Interspecific Competition in Tits Parus spp. and the goldcrest

651 Regulus regulus: Foraging Shifts in Multispecific Flocks. Oikos, 37(3), 335-344.

652

653 Baker, M. C., \& Becker, A. M. (2002). Mobbing calls of black-capped chickadees:

654 Effects of urgency on call production. The Wilson Bulletin, 114(4), 510-516.

655

656 Bartmess-LeVasseur, J., Branch, C. L., Browning, S. A., Owens, J. L., \& Freeberg, T.

657 M. (2010). Predator stimuli and calling behavior of Carolina chickadees (Poecile

658 carolinensis), tufted titmice (Baeolophus bicolor), and white-breasted nuthatches

659 (Sitta carolinensis). Behavioral Ecology and Sociobiology, 64(7), 1187-1198.

660 http://doi.org/10.1007/s00265-010-0935-y

661

662 Bates, D., Maechler, M., Bolker, B. M., \& Walker, S. (2014, September 30). lme4:

663 Linear mixed-effects models using “Eigen” and S4.

664

665 Billings, A. C., Greene, E., \& La Lucia Jensen, De, S. M. (2015). Are chickadees

666 good listeners? Antipredator responses to raptor vocalizations. Animal Behaviour,

667 110, 1-8. http://doi.org/10.1016/j.anbehav.2015.09.004

668

669 Bioacoustics Research Program. (2014, September 30). Raven Pro: Interactive Sound 670 Analysis Software (Version 1.5). Ithaca, NY: The Cornell Lab of Ornithology. 
672 Blumstein, D. T. (2007). The Evolution, Function, and Meaning of Marmot Alarm

673 Communication. In Advances in the Study of Behavior Vol. 37 (Vol. 37, pp. 371-

674 401). Elsevier. http://doi.org/10.1016/S0065-3454(07)37008-3

675

676 Blumstein, D. T., \& Armitage, K. B. (1997). Alarm calling in yellow-bellied

677 marmots: I. The meaning of situationally variable alarm calls. Animal Behaviour, $678 \quad 53,143-171$.

679

680 Book, D. L., \& Freeberg, T. M. (2015). Titmouse calling and foraging are affected by 681 head and body orientation of cat predator models and possible experience with real 682 cats. Animal Cognition, 18(5), 1155-1164. http://doi.org/10.1007/s10071-015$683 \quad 0888-7$

684

685 Clemmons, J. R., \& Lambrechts, M. M. (1992). The waving display and other nest 686 site anti-predator behavior of the black-capped chickadee. The Wilson Bulletin, $687 \quad 104(4), 749-756$.

688

689 Courter, J. R., \& Ritchison, G. (2010). Alarm calls of tufted titmice convey 690 information about predator size and threat. Behavioral Ecology, 21(5), 936-942.

691

692 Cramp, S. (1993). Handbook of the birds of Europe the Middle East and North Africa.

693 (C. M. Perrins, D. J. Brooks, E. Dunn, R. Gillmor, J. Hall-Craggs, B. Hillcoat, et 694 al., Eds.) Oxford, New York: Oxford University Press.

695

696 Curio, E. (1978). The adaptive significance of avian mobbing. I. Teleonomic 
697 hypotheses and predictions. Zeitschrift Fur Tierpsychologie, 48, 175-183.

698

699 Curio, E., Klump, G. M., \& Regelmann, K. (1983). An anti-predator response in the 700 great tit (Parus major): is it tuned to predator risk? Oecologia, 60(1), 83-88.

701

702 Deadman, A. J. (1973). A population study of the coal tit (Parus ater) and crested tit 703 (Parus cristatus) in a Scottish pine plantation (Doctoral thesis). Aberdeen, U.K.:

$704 \quad$ University of Aberdeen.

705

706 Ekman, J. (1979). Coherence, composition and territories of winter social groups of

707 the willow tit Parus montanus and the crested tit P. cristatus. Ornis Scandinavica, $708 \quad 10(1), 56-68$.

709

710 Ekman, J. (1989). Ecology of non-breeding social systems of Parus. The Wilson 711 Bulletin, 101(2), 263-288.

712

713 Evans, C. S., Macedonia, J. M., \& Marler, P. (1993). Effects of apparent size and

714 speed on the response of chickens, Gallus gallus, to computer-generated

715 simulations of aerial predators. Animal Behaviour, 46, 1-11.

716

717 Feise, R. J. (2002). Do multiple outcome measures require p-value adjustment. BMC 718 Medical Research Methodology, 2(8), 1-4.

719

720 Ficken, M. S., Hailman, E. D., \& Hailman, J. P. (1994). The chick-a-dee call system 721 of the Mexican chickadee. Condor, 96(1), 70-82. 
723 Fisher, D. J. (1982). Report on roving tit flocks project. British Birds, 75, 370-374.

724

725 Freckleton, R. P., Harvey, P. H., \& Pagel, M. (2002). Phylogenetic Analysis and

726 Comparative Data: A Test and Review of Evidence. American Naturalist, 160(6),

727 712-726. http://doi.org/10.1086/343873

728

729 Freeberg, T. M., \& Harvey, E. M. (2008). Group size and social interactions are

730 associated with calling behavior in Carolina chickadees (Poecile carolinensis).

731 Journal of Comparative Psychology, 122(3), 312-318.

$732 \quad$ http://doi.org/10.1037/0735-7036.122.3.312

733

734 Furrer, R. D., \& Manser, M. B. (2009). The evolution of urgency- based and

735 functionally referential alarm calls in ground- dwelling species. American

736 Naturalist, 173(3), 400-410. http://doi.org/10.1086/596541

737

738 Gibb, J. A. (1960). Populations of tits and goldcrests and their food supply in pine 739 plantations. Ibis, 102(2), 163-208.

740

741 Gill, S. A., \& Bierema, A. M. K. (2013). On the meaning of alarm calls: a review of 742 functional reference in avian alarm calling. Ethology, 119, 449-461.

743

744 Gill, S. A., \& Sealy, S. G. (2004). Functional reference in an alarm signal given 745 during nest defense: seet calls of yellow warblers denote brood-parasitic brown- 
746 headed cowbirds. Behavioral Ecology and Sociobiology, 56(1), 71-80.

747

748 Goodale, E., \& Kotagama, S. W. (2005a). Alarm calling in Sri Lankan mixed-species 749 bird flocks. Auk, 122(1), 108-120.

750

751 Goodale, E., \& Kotagama, S. W. (2005b). Testing the roles of species in mixed752 species bird flocks of a Sri Lankan rain forest. Journal of Tropical Ecology, 21(6), $753 \quad 669-676$.

754

755 Goodale, E., Beauchamp, G., Magrath, R. D., Nieh, J. C., \& Ruxton, G. D. (2010). 756 Interspecific information transfer influences animal community structure. Trends 757 in Ecology \& Evolution, 25(6), 354-361. http://doi.org/10.1016/j.tree.2010.01.002 758

759 Graham, I. M., Redpath, S. M., \& Thirgood, S. J. (1995). The diet and breeding 760 density of Common Buzzards Buteo buteo in relation to indices of prey abundance. 761 Bird Study, 42(2), 165-173. http://doi.org/10.1080/00063659509477162

762

763 Griesser, M. (2008). Referential calls signal predator behavior in a group-living bird 764 species. Current Biology, 18(1), 69-73.

765

766 Haftorn, S. (1993). Ontogeny of the vocal repertoire in the willow tit Parus montanus. 767 Ornis Scandinavica, 24(4), 267-289.

768

769 Hailman, J. P. (1989). The Organization of Major Vocalizations in the Paridae. The $770 \quad$ Wilson Bulletin, 101(2), 305-343. 
771

772 Hailman, J. P., \& Ficken, M. S. (1996). Comparative Analysis of Vocal Repertoires,

773 with Reference to Chickadees. In D. E. Kroodsma \& E. H. Miller (Eds.), Ecology

774 and Evolution of Acoustic Communication in Birds (pp. 136-159). Ithaca.

775

776 Hetrick, S. A., \& Sieving, K. E. (2011). Antipredator calls of tufted titmice and 777 interspecific transfer of encoded threat information. Behavioral Ecology, 23(1), 778 83-92.

779

780 Johansson, U. S., Ekman, J., Bowie, R. C. K., Halvarsson, P., Ohlson, J. I., Price, T.

781 D., \& Ericson, P. G. P. (2013). A complete multilocus species phylogeny of the tits

782 and chickadees (Aves: Paridae). Molecular Phylogenetics and Evolution, 69(3),

783 852-860. http://doi.org/10.1016/j.ympev.2013.06.019

784

785 Klump, G. M., \& Shalter, M. D. (1984). Acoustic behaviour of birds and mammals in 786 the predator context. Zeitschrift Fur Tierpsychologie - Journal of Comparative $787 \quad$ Ethology, 66, 189-226.

788

789 Langham, G. M., Contreras, T. A., \& Sieving, K. E. (2006). Why pishing works:

790 Titmouse (Paridae) scolds elicit a generalized response in bird communities.

$791 \quad$ Ecoscience, 13(4), 485-496.

792

793 Latimer, W. (1977). A comparative study of the songs and alarm calls of some Parus $794 \quad$ species. Zeitschrift Fur Tierpsychologie, 45, 414-433. 
796 le Roux, A., Cherry, M. I., \& Manser, M. B. (2008). The audience effect in a

797 facultatively social mammal, the yellow mongoose, Cynictis penicillata. Animal

798 Behaviour, 75(3), 943-949. http://doi.org/10.1016/j.anbehav.2007.07.014

799

800 Lima, S. L. (1993). Ecological and evolutionary perspectives on escape from

801 predatory attack: a survey of North American birds. The Wilson Bulletin, 105(1),

$802 \quad 1-47$.

803

804 Magrath, R. D., Haff, T. M., Fallow, P. M., \& Radford, A. N. (2014). Eavesdropping

805 on heterospecific alarm calls: from mechanisms to consequences. Biological

806 Reviews, 90(2), 1-27. http://doi.org/10.1111/brv.12122

807

808 Manser, M. B. (2001). The acoustic structure of suricates' alarm calls varies with

809 predator type and the level of response urgency. Proceedings of the Royal Society

810 B:Biological Sciences, 268(1483), 2315-2324.

811

812 Manser, M. B., Jansen, D. A. W. A. M., Graw, B., Hollén, L. I., Bousquet, C. A. H.,

813 Furrer, R. D., \& le Roux, A. (2014). Vocal Complexity in Meerkats and Other

814 Mongoose Species. Advances in the Study of Behavior (1st ed., Vol. 46, pp. 281-

815 310). Elsevier Inc. http://doi.org/10.1016/B978-0-12-800286-5.00006-7

816

817 Marler, P. (1955). Characteristics of some animal calls. Nature, 176(4470), 6-8.

818

819 Marler, P. (1967). Animal communication signals. Science, 157(3790), 769-774.

820 
821 Marler, P., Evans, C. S., \& Hauser, M. D. (1992). Animal signals: Motivational,

822 referential, or both? In H. Papoušek, U. Jürgens, \& M. Papoušek (Eds.), Nonverbal

823 Vocal Communication: Comparative and Developmental Approaches (pp. 64-84).

824 Cambridge: Cambridge University Press.

825

826 Millon, A., Nielsen, J. T., Bretagnolle, V., \& Møller, A. P. (2009). Predator-prey

827 relationships in a changing environment: the case of the sparrowhawk and its avian

828 prey community in a rural area. Journal of Animal Ecology, 78(5), 1086-1095.

829 http://doi.org/10.1111/j.1365-2656.2009.01575.x

830

831 Morse, D. H. (1978). Structure and foraging patterns of flocks of tits and associated

832 species in an English woodland during the winter. Ibis, 120(3), 298-312.

833 http://doi.org/10.1111/j.1474-919X.1978.tb06790.x

834

835 Münkemüller, T., Lavergne, S., Bzeznik, B., Dray, S., Jombart, T., Schiffers, K., \&

836 Thuiller, W. (2012). How to measure and test phylogenetic signal. Methods in

837 Ecology and Evolution, 3(4), 743-756. http://doi.org/10.1111/j.2041-

$838 \quad$ 210X.2012.00196.x

839

840 Murphy, D., Lea, S. E. G., \& Zuberbühler, K. (2013). Male blue monkey alarm calls

841 encode predator type and distance. Animal Behaviour, 85(1), 119-125.

842 http://doi.org/10.1016/j.anbehav.2012.10.015

843

844 Nakagawa, S., \& Schielzeth, H. (2010). Repeatability for Gaussian and non-Gaussian 845 data: a practical guide for biologists. Biological Reviews, 85, 935-956. 
847

848 Nakagawa, S., \& Schielzeth, H. (2012). A general and simple method for obtaining $\mathrm{R}^{2}$ 849 from generalized linear mixed-effects models. Methods in Ecology and Evolution, $850 \quad 4(2), 133-142$. http://doi.org/10.1111/j.2041-210x.2012.00261.x

851

852 Nakamura, T. (1970). A study of Paridae community in Japan, 141-169.

853

854 Owings, D. H., \& Virginia, R. A. (1978). Alarm calls of California ground squirrels 855 (Spermophilus beecheyi). Zeitschrift Fur Tierpsychologie, 46(1), 58-70.

856

857 Pagel, M. (1999). Inferring the historical patterns of biological evolution. Nature, 401, $858 \quad 877-884$.

859

860 Peres, C. A. (1993). Anti-predation benefits in a mixed-species group of Amazonian 861 tamarins. Folia Primatologica; International Journal of Primatology, 61(2), 6186276.

863

864 Perneger, T. V. (1998). What's wrong with Bonferroni adjustments. British Medical 865 Journal, 316(7139), 1236-1238. http://doi.org/10.1136/bmj.316.7139.1236

866

867 Perrins, C. M. (1979). British Tits. (M. Davies, J. Gilmour, K. Mellanby, \& E.

868 Hosking, Eds.) (1st ed.). London, U.K.: William Collins Sons \& Co. Ltd. 869

870 Petty, S. J., Patterson, I. J., Anderson, D. I. K., Little, B., \& Davison, M. (1995). 
871 Numbers, breeding performance, and diet of the sparrowhawk Accipiter nisus and

872 merlin Falco columbarius in relation to cone crops and seed-eating finches. Forest 873 Ecology and Management, 79, 133-146.

874

875 Placer, J., \& Slobodchikoff, C. N. (2000). A fuzzy-neural system for identification of 876 species-specific alarm calls of Gunnison's prairie dogs. Behavioural Processes, 52, $877 \quad 1-9$.

878

879 Placer, J., \& Slobodchikoff, C. N. (2004). A method for identifying sounds used in the $880 \quad$ classification of alarm calls. Behavioural Processes, 67(1), 87-98.

881 http://doi.org/10.1016/j.beproc.2004.03.001

882

883 R Core Team. (2014). R: A language and environment for statistical computing (3rd 884 ed.). Vienna, Austria: R Foundation for Statistical Computing.

885

886 Randler, C. (2012). A possible phylogenetically conserved urgency response of great

887 tits (Parus major) towards allopatric mobbing calls. Behavioral Ecology and 888 Sociobiology, 66(5), 675-681.

889

890 Rothman, K. J. (1990). No adjustments are needed for multiple comparisons.

$891 \quad$ Epidemiology, 1(1), 43-46.

892

893 Seyfarth, R. M., \& Cheney, D. L. (2003). Signalers and receivers in animal 894 communication. Annual Review of Psychology, 54, 145-173. 895 
896 Seyfarth, R. M., Cheney, D. L., \& Marler, P. (1980). Vervet monkey alarm calls:

897 Semantic communication in a free-ranging primate. Animal Behaviour, 28(4),

$898 \quad$ 1070-1094.

899

900 Shelly, E. L., \& Blumstein, D. T. (2005). The evolution of vocal alarm

901 communication in rodents. Behavioral Ecology, 16(1), 169-177.

902 http://doi.org/10.1093/beheco/arh148

903

904 Sieving, K. E., Hetrick, S. A., \& Avery, M. L. (2010). The versatility of graded

905 acoustic measures in classification of predation threats by the tufted titmouse

906 Baeolophus bicolor: exploring a mixed framework for threat communication.

907 Oikos, 119(2), 264-276.

908

909 Slobodchikoff, C. N. (2010). Alarm calls in mammals and birds. Encyclopedia of

910 Animal Behavior, 40-43.

911

912 Soard, C. M., \& Ritchison, G. (2009). Chick-a-dee calls of Carolina chickadees

913 convey information about degree of threat posed by avian predators. Animal

914 Behaviour, 78(6), 1447-1453.

915

916 Sullivan, K. (1985). Selective alarm calling by downy woodpeckers in mixed-species

917 flocks. Auk, 184-187.

918

919 Suzuki, T. N. (2012). Referential mobbing calls elicit different predator-searching

920 behaviours in Japanese great tits. Animal Behaviour, 84(1), 53-57. 
921

922 Suzuki, T. N. (2014). Communication about predator type by a bird using discrete,

923 graded and combinatorial variation in alarm calls. Animal Behaviour, 87, 59-65.

924

925 Suzuki, T. N. (2016). Semantic communication in birds: evidence from field research

926 over the past two decades. Ecological Research, 1-14.

927

928 Suzuki, T. N., \& Ueda, K. (2013). Mobbing calls of Japanese tits signal predator type:

929 field observations of natural predator encounters. The Wilson Journal of

$930 \quad$ Ornithology, 125(2), 412-415.

931

932 Suzuki, T. N., Wheatcroft, D. J., \& Griesser, M. (2016). Experimental evidence for

933 compositional syntax in bird calls. Nature Communications, 7, 1-7.

934 http://doi.org/10.1038/ncomms10986

935

936 Swann, R. L., \& Etheridge, B. (2009). A comparison of breeding success and prey of

937 the Common Buzzard Buteo buteo in two areas of northern Scotland. Bird Study,

938 42(1), 37-43. http://doi.org/10.1080/00063659509477146

939

940 Šálek, M., Marhoul, P., Pintíř, J., Kopecký, T., \& Slabý, L. (2004). Importance of

941 unmanaged wasteland patches for the grey partridge Perdix perdix in suburban

942 habitats. Acta Oecologica, 25(1-2), 23-33.

943 http://doi.org/10.1016/j.actao.2003.10.003

944

945 Templeton, C. N., Greene, E., \& Davis, K. (2005). Allometry of alarm calls: black- 
946 capped chickadees encode information about predator size. Science, 308(5730),

$947 \quad 1934-1937$.

948

949 Townsend, S. W., \& Manser, M. B. (2013). Functionally referential communication in 950 mammals: the past, present and the future. Ethology, 119(1), 1-11.

951 http://doi.org/10.1111/eth.12015

952

953 Wilson, D. R., \& Mennill, D. J. (2011). Duty cycle, not signal structure, explains

954 conspecific and heterospecific responses to the calls of black-capped chickadees

955 (Poecile atricapillus). Behavioral Ecology, 22(4), 784-790.

956

957 Yorzinski, J. L., \& Vehrencamp, S. L. (2009). The effect of predator type and danger 958 level on the mob calls of the American crow. Condor, 111(1), 159-168.

959 http://doi.org/10.1525/cond.2009.080057

960

961

962

963

964

965

966

967

968 


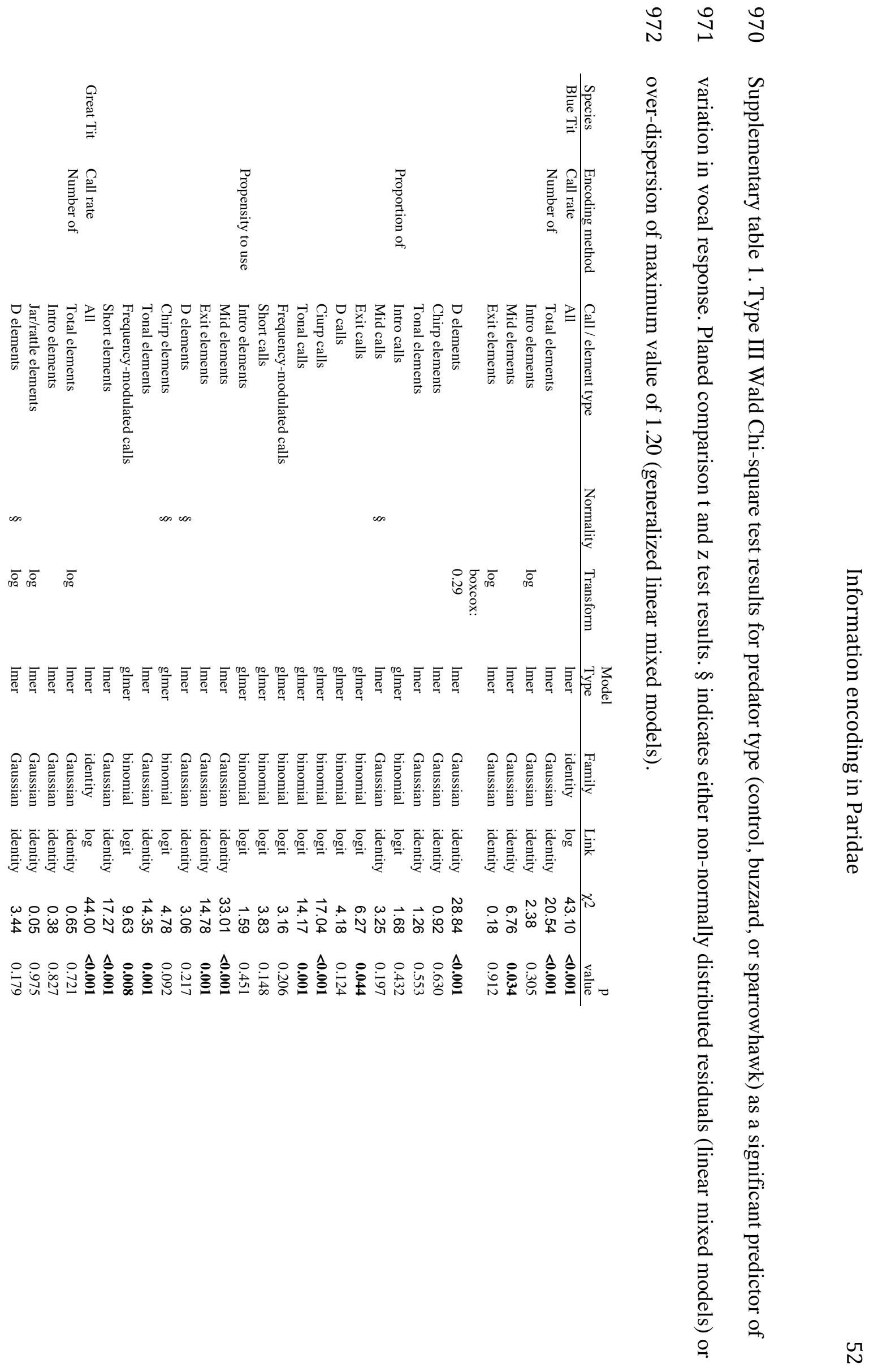




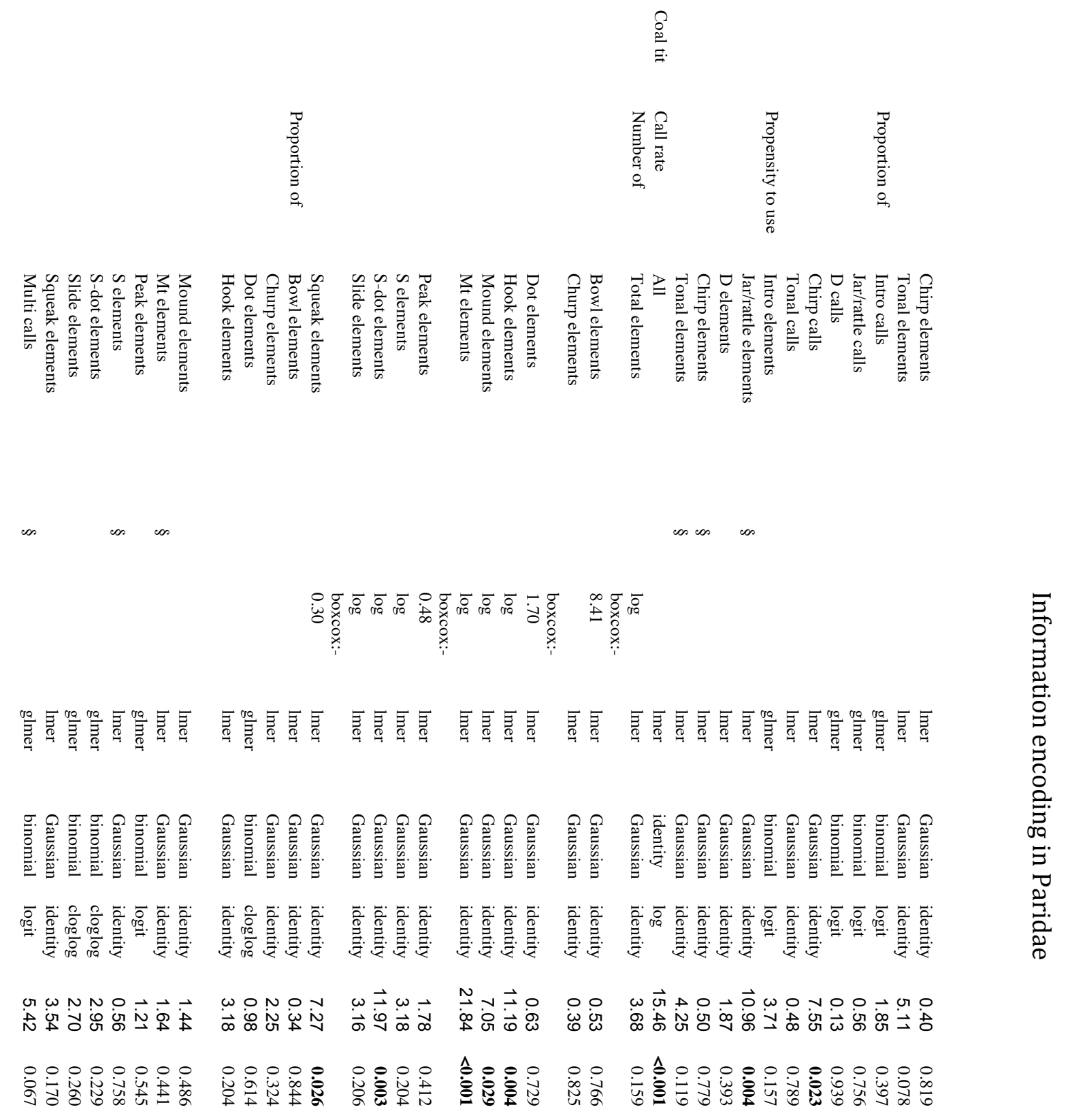



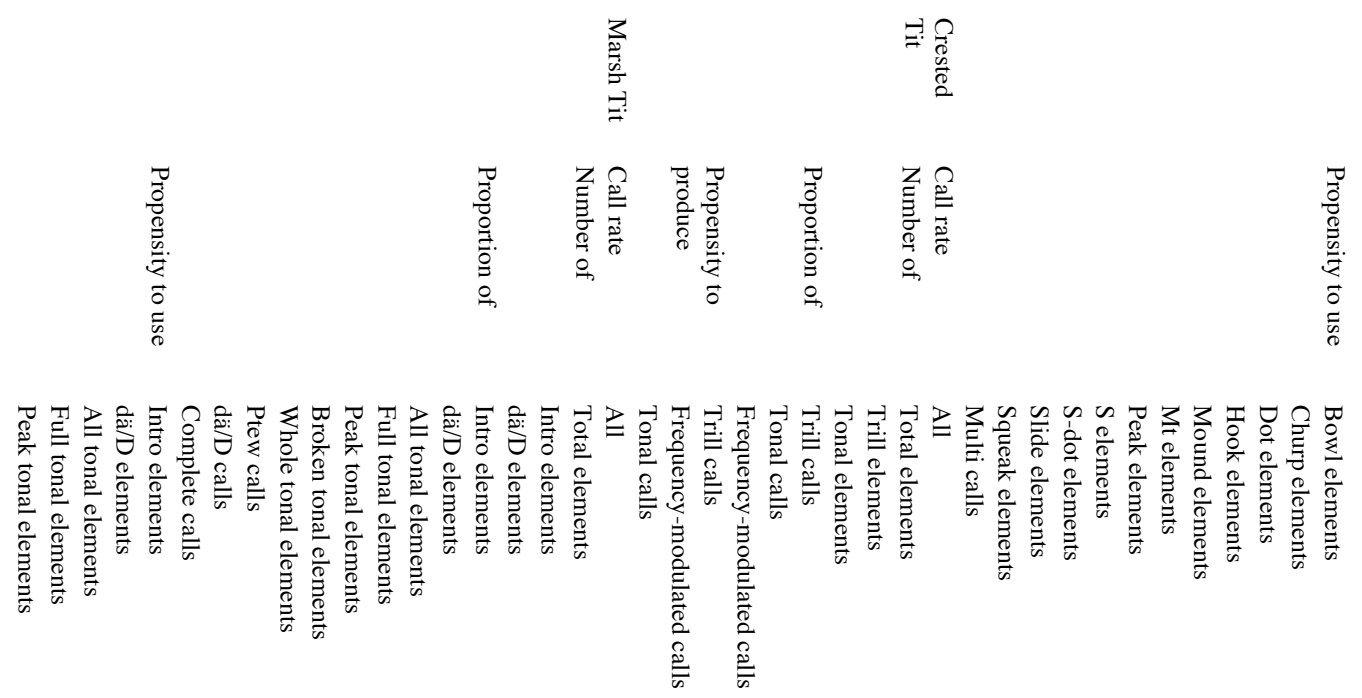

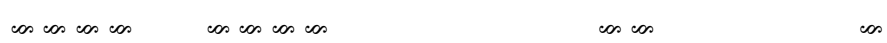

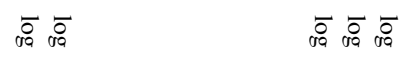

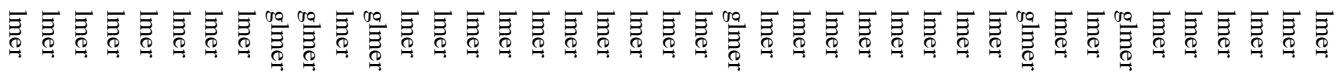

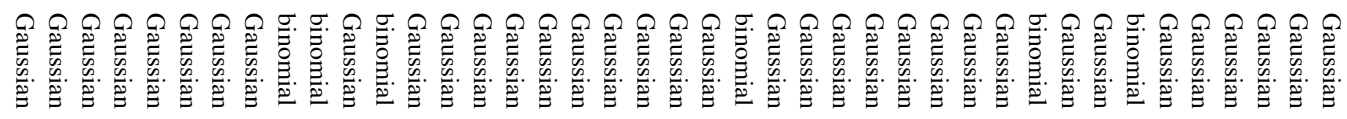
IIIIIII

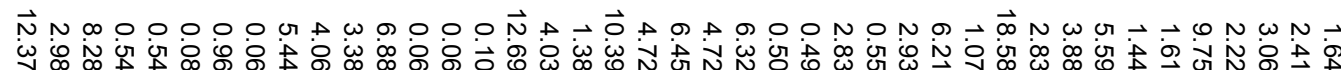

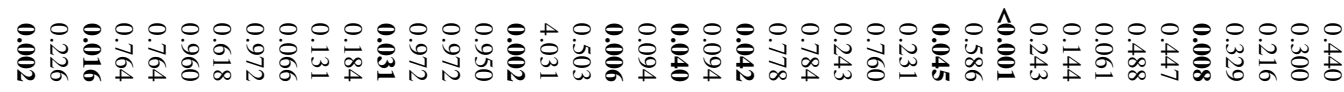


$\stackrel{ొ}{\omega}$

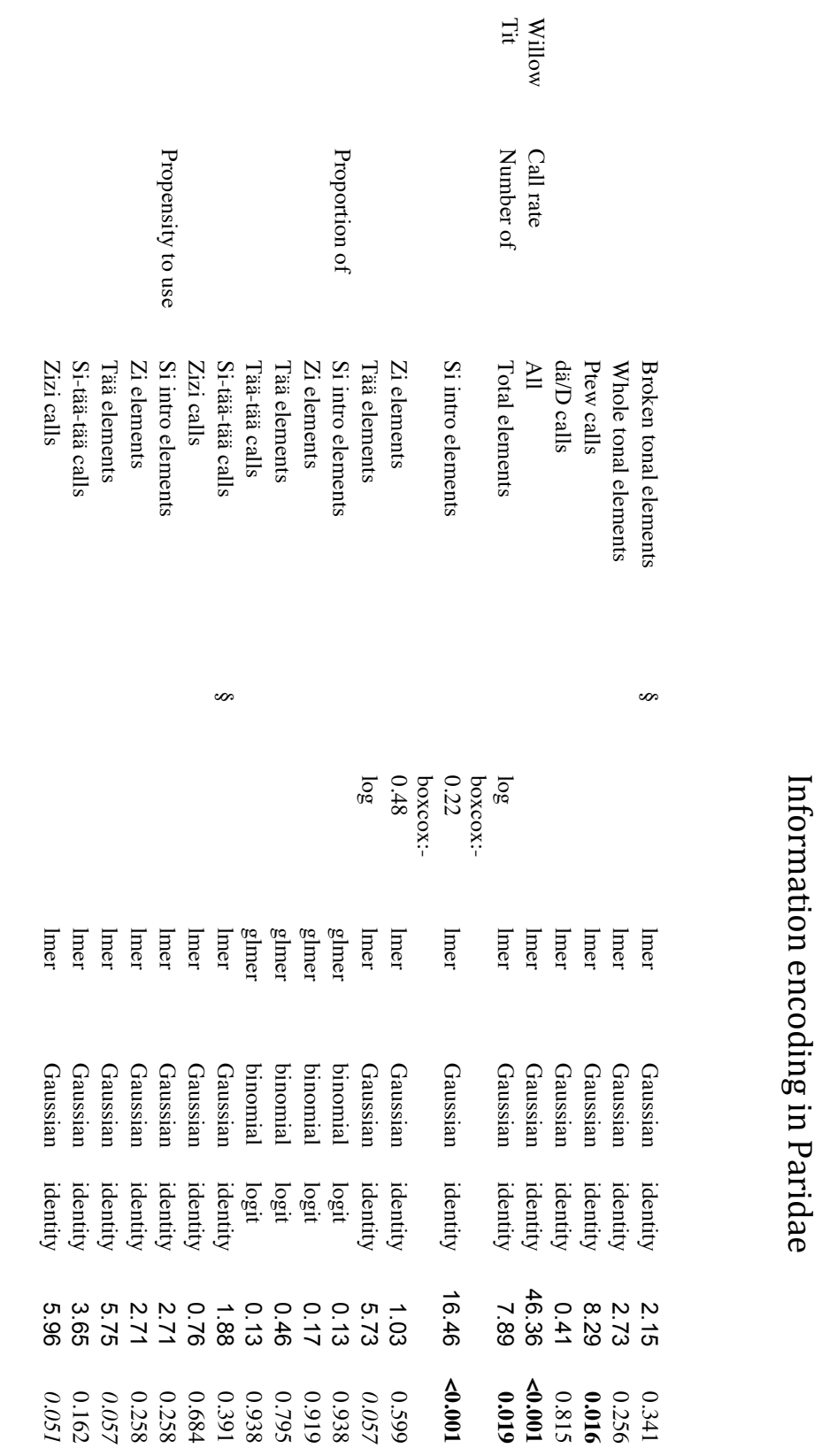




\section{Acknowledgements}

3 We thank the Richard K Broughton, St Andrews Botanic Garden, the Rothiemurchus

4 Estate, Cublin Forest, Boat of Garten, the National Parks \& Reserve managers, the

5 Forestry Comission, Scottish National Heritage, Yorkshire and Northumberland Wildlife

6 Trusts, and many homeowners for providing access to their gardens and lands. We are

7 grateful Erick Greene for the idea to use 'robo-raptors' and his help designing them and

8 George Jamieson who created the taxidermy mounts. We also thank members of the

9 Healy and Templeton labs for helpful suggestions on the experimental design and

10 interpretation, and Dr. Michael Morrissey for his advice on statistical models. Finally we

11 thank Scott MacDougall-Shackleton, Toshitaka Suzuki, and an anonymous reviewer for

12 their constructive comments on earlier versions of the manuscript. This research was

13 approved by the University of St Andrews School of Biology Ethics Committee

14 (01112013) and funded by NERC (NE/J018694/1), the Royal Society (RG2012R2), the

15 M. J. Murdock Charitable Trust (2014199), and the University of St Andrews (University

16 of St Andrews $600^{\text {th }}$ Year Scholarship and the St Leonard's Fee Scholarship). 